\title{
Restraint stress induces uterine microenvironment disorder in mice during early pregnancy through the $\beta 2$-AR/cAMP/PKA pathway
}

Jiayin Lu

China Agricultural University

Guanhui Liu

China Agricultural University

Zixu Wang

China Agricultural University

Jing Cao

China Agricultural University

Yaoxing Chen

China Agricultural University

Yulan Dong ( $\nabla$ ylbcdong@cau.edu.cn )

\section{Research}

Keywords: restraint stress, $\beta 2$-AR/cAMP/PKA, pregnancy, apoptosis, uterus

Posted Date: January 8th, 2020

DOI: https://doi.org/10.21203/rs.2.20359/v1

License: (9) This work is licensed under a Creative Commons Attribution 4.0 International License.

Read Full License 


\section{Abstract}

\section{Background}

According to statistics, one in four people worldwide suffers from mental illness, and the probability of a pregnant women experiencing mental illness is much higher than that of others. However, research on the mechanism of female reproductive diseases caused by stress is still incomplete.

\section{Methods}

In our work, a restraint stress model was used to simulate psychological stress. Western blotting, immunohistochemistry, and ELISA were used to explore whether restraint stress causes uterine microenvironment disorders in pregnant females. $\beta 2$-AR agonists and blockers, cAMP agonists, PKA blockers, ERK blockers and NF-KB p65 blockers were used to explore whether stress initiates the $\beta 2$ AR/cAMP/PKA signaling pathway in endometrial stromal cells. To analyze the effects of restraint stress and gestational age on the experimental data, two-way analysis of variance (ANOVA) followed by Duncan's post hoc test was performed. The difference between control and stressed mice at the same gestational age was evaluated by independent sample $t$ test.

Results

Restraint stress caused the weight of pregnant mice to be reduced, and the blood glucose and NE levels were increased. Also, the mRNA and protein levels of $\beta 2$-AR, an adrenergic receptor, were increased. The protein level of MMP-9 was decreased, and the protein levels of pERK1/2, Caspase-3 and pNF-KB p65 were increased. In vitro studies showed that after $\beta 2$-AR was activated, the ERK $1 / 2$ and Caspase-3 levels were increased. However, they were decreased when PKA was blocked. The protein level of Caspase-3 was reduced when ERK and NF-KB were blocked.

\section{Conclusions}

Restraint stress induces uterine microenvironment disorder. The $\beta 2$-AR/cAMP/PKA pathway promotes apoptosis and affects the development of the uterus through the ERK and NF-KB signaling pathway, and this may cause embryonic dysplasia. The findings of this study may provide evidence for reproduction under psychological stress.

\section{Introduction}

Psychological stress has become a major public health concern worldwide. Emily A. Holmes et al. argued that mental health science should be emphasized. One in four people worldwide experience the effects of mental health disorders, including posttraumatic stress disorder (PTSD), obsessive-compulsive disorder (OCD), eating disorders, schizophrenia and depression. Mental health disorders account for more than $15 \%$ of the disease burden in developed countries, more than all forms of cancer [1, 2]. In particular, pregnant women are susceptible to mental illness such as depression and anxiety in adverse 
environments [3]. A study showed that $25 \%$ of women in Sweden experience a miscarriage before the age of 39 [4]. Remarkably, infertility affects one in four couples in developing countries [5]. However, it was an overlooked issue until the 1990s [6]. According to the NCBI database, 3686 related articles were published in the past 10 years, with 2015 articles being published in the past 5 years. This shows that psychological stress is receiving more attention from researchers. Most of the studies on psychological stress during pregnancy involved offspring, focusing on preterm birth, pregnancy loss, fetal growth restriction, and low birthweight [7]. However, only 579 studies focused on pregnant women. Thus, more concern should be paid to the impact of psychological stress on pregnant women during pregnancy.

Meanwhile, during early pregnancy and placenta formation, the level of local ROS (Reactive oxygen species) in the uterus is higher, inducing oxidative stress, while the content of the antioxidant substance T-SOD (total superoxide dismutase) increases, maintaining the local oxidant-antioxidant balance of the uterus [8]. Disruption of the oxidant/antioxidant ratio is thought to be involved in the pathophysiology of schizophrenia and OCD [9]. Liu et al. also found that in early pregnancy, maternal uterine antioxidant capacity is decreased and MDA (malondialdehyde) levels are increased under restraint stress, causing severe oxidative stress, decreasing the immune level of the uterine microenvironment and affecting fetal implantation [10]. Therefore, the mechanism underlying the association between stress and poor pregnancy outcomes may be oxidative stress [11]. In fact, psychological stress (restraint stress) is known to be a major risk factor for several psychiatric diseases due to increased glucocorticoid neurotoxicity [12]. Both in vivo and in vitro studies have shown that CORT (corticosterone) can enhance cell apoptosis and neurotoxicity by increasing oxidative stress and the generation of ROS [13, 14]. Chronic stress can induce constant release of glucocorticoids and cause many serious health problems, such as mental disorders, cardiovascular diseases and autoimmune diseases. Many studies have suggested that the neurotoxic effect of corticosterone is mediated by increased oxidative stress and apoptosis [15]. Additionally, norepinephrine (NE) is another marker of stress development. Increased circulation of NE, found in the diseased heart as a result of sympathetic nervous system overactivation, is responsible for cell death and oxidative stress [16]. Meanwhile, a report indicated that plasma EPI (epinephrine) and NE levels are elevated among pregnant women with preeclampsia or gestational hypertension compared to healthy pregnant women [17]. Endogenous catecholamines such as EPI and NE are released from the adrenal gland and sympathetic nervous system under stress. NE and EPI combine with their corresponding receptors and cause further intracellular signal transduction. NE and EPI stimulate $a\left(a_{1 A}\right.$, $a_{1 B}, a_{1 D}, a_{2 A}, a_{2 B}$, and $\left.a_{2 C}\right)$ - and $\beta\left(\beta_{1}, \beta_{2}\right.$, and $\beta_{3}$ )-adrenergic receptors (ARs) with differing affinities [18]. Additionally, Chen et al. found that the mRNA expression of $\beta_{2}-A R\left(\beta_{2}\right.$-adrenergic receptor) is much higher than that of other subtypes in the uteri of E4 mice [19]. Therefore, $\beta_{2}-A R$ has become an important receptor for studying local stress in the uterus.

During pregnancy, the balance between cell proliferation and death is crucial for successful embryo implantation and the maintenance of pregnancy [20]. In our previous studies, restraint stress was shown to disturb the adaptive reconstruction of the endometrium during implantation in maternal mice [21] and to be associated with oxidative stress-induced immune dysfunction and an imbalance between cell 
proliferation and apoptosis [10, 21]. $\beta_{2}$-AR activates adenylyl cyclase (AC) by triggering the coupling of the receptor to Gs. AC converts ATP to cAMP (cyclic adenosine monophosphate). cAMP, a second messenger, activates cAMP-dependent protein kinase A (PKA) [22]. $\beta_{2}$-AR/Gs/cAMP/PKA-dependent signaling inhibits cell proliferation [23]. Meanwhile, the cAMP/PKA pathway induces apoptosis in cardiac myocytes. $\beta_{1}-A R$ is involved in the induction of apoptosis of adult cardiac myocytes, while the $\beta_{2}-A R$ receptor pathway is antiapoptotic [24]. In another study, $\beta_{2}$-AR was shown to activate pro-survival kinases and attenuate mitochondrial dysfunction during oxidative stress [25]. However, a study showed that the activation of $\beta_{2}-A R$ is detrimental to cardiac and skeletal muscles through the induction of apoptosis [26]. Therefore, the role of $\beta_{2}$-AR-mediated oxidative stress in the mechanism of apoptosis is unknown.

Chronic intermittent hypoxia $(\mathrm{ClH})$ can markedly increase the $\beta_{2}-A R / \beta_{1}-A R$ ratio and the phosphorylation of ERK1/2 (extracellular regulated protein kinases 1/2) and p38. Meanwhile, COX-2 (Cyclooxygenase 2) is increased via the $\beta_{2}-\mathrm{AR} / \mathrm{Gi}$-mediated stimulation of the ERK/p38 pathway during the process [27]. ROS participates in mitogen-activated protein kinase (MAPK) activation [28]. A study demonstrated the involvement of the MEK/ERK1/2 signaling pathway in anti-HCV status induced by oxidative stress elicited by a broad range of anti-HCV reagents [29]. Additionally, the activation of the MAPK signaling pathway, including JNK and ERK, promotes cell apoptosis (by promoting proteins including Caspase-9 and Caspase-3) [30]. Activated Caspase-3 can initiate mitochondrial apoptosis in cells. The release of cytochrome c may depend on a reduction in MMP-9 (Matrix metalloproteinase 9) [31]. Oxidative stress induces redox-sensitive MMP-9 stimulation, leading to receptor for advanced glycation end-products (RAGE) shedding into soluble and nuclear forms and subsequently to nuclear factor-KB (NF-KB) activation and the secretion of various cytokines [32]. Similarly, in our previous study, oxidative stress induced by restraint stress was shown to lead to immune dysfunction [10]. In addition, a study found that MMP-9 can promote the invasion of extravillous trophoblast cells into the endometrium and promote implantation [33]. Therefore, the mechanism by which restraint stress-induced oxidative stress disturbs the balance of the uterine microenvironment is important.

However, the mechanisms by which restraint stress causes microenvironment disorders in the uterus are unclear. Thus, in this work, a model of restraint stress was established in mice, and we mainly studied the role of $\beta_{2}-A R$ in the proliferation/apoptosis disorders and an imbalance between oxidants/antioxidants caused by restraint stress during early pregnancy.

\section{Materials And Methods}

\section{Animal treatments}

A total of 250 female and 80 male ICR mice (8 weeks of age; Vital River Laboratory Animal Technology Co. Ltd., Beijing, China) were housed under conventional conditions (at a relative humidity of $50 \pm 10 \%$, a temperature of $21 \pm 1^{\circ} \mathrm{C}$ ) on a regular 10-h dark:14-h light cycle (with lights on at 7:00 A.M.). First, the mice were maintained in a room for a week to allow them to adapt to the environment. Estrus mice were 
placed with a sexually experienced male at night, and females with vaginal sperm plugs the following morning were considered to be at E1 (Embryonic 1d). Female mice were individually placed into ventilated transparent plastic centrifuge tubes (they were able to breathe freely but were unable to escape) to limit their movements for $4 \mathrm{~h}$ (from 8:00 A.M. to 12:00 P.M.), and water and food were withheld. The control females were left untreated in their home cages without water or food for $4 \mathrm{~h}$ every day. Restraint stress was initiated on E1 and continued until the mice were sacrificed on E3 (Embryonic day 3), E5 (Embryonic day 5) and E7 (Embryonic day 7) (Fig. 1). The weights of the mice were measured and recorded before and after restraint stress every day. All animal procedures were approved by the China Agricultural University Institutional Animal Care and Use Committee (AW18079102-3-2).

\section{Plasma and tissue preparations}

A total of 60 pregnant females were anesthetized by $2 \%$ pentobarbital ( $4 \mathrm{~mL} / \mathrm{kg}$ body weight) on E5, E7 and E7 immediately following restraint stress. Blood glucose levels in the tail blood were measured by a Roche blood glucose meter (GC14906201, ACCU-CHEK Active, Roche, Germany) before sacrifice. Plasma samples were collected to detect NE. Some of the uterine specimens, excluding the embryos, were rapidly dissected and stored at $-80^{\circ} \mathrm{C}$ for protein analysis and mRNA analysis. Some of the uterine specimens were rapidly obtained and stored at $4 \%$ paraformaldehyde for morphological analysis.

\section{Reverse transcription-polymerase chain reaction (RT-PCR)}

Total RNA was extracted using TRIzon reagent (CW0580A, CoWin Biotech Co., Inc., Beijing, China). cDNA was synthesized using reverse transcription kits (A5001, Promega Biotech Co., Ltd., USA). Primers were synthesized by Invitrogen Trading of Shanghai. RT-PCR was performed with SYBR Green Master Mix (M7122, Promega, WI, USA), Bench Top 100 bp DNA Ladder (G8291, Promega, WI, USA) was used to determine the size of the DNA. Seven tissue samples were included in each group. Each sample was tested in triplicate.

The following RT-PCR primers were used in these assays: $\beta_{1}$-AR (forward:5'-CCTTTCGC TACCAGAGTTTGC-3'; reverse: 5'-CACTTGGGGTCGTTGTAGCAG-3'), $\beta_{2}$-AR (forward: 5'TCACTCAGGAACGGGACGAAG-3'; reverse: 5'-CAGCACACGCCAAGGAGATTATG-3'), $\beta_{3}$-AR (forward: 5'CACGCCGAGACTACAGACC-3'; reverse: 5' -CAACCAGTTTCGCCCAA G-3'), $\beta$-actin (forward: 5'TGCTGTCCCTGTATGCCTCTG-3'; reverse: 5'-TTGATGTCACG CACGATTTCC-3').

\section{Measurement of plasma NE}

The total plasma NE concentrations were detected by using a mouse NE competitive ELISA (enzymelinked immunosorbent assay) Kit (CEA907Ge, Uscn Life Science Inc., Wuhan, China). All tests were performed according to the kit's instructions. The limit of detection for the assay ranged from 6.17 to $5000 \mathrm{pg} / \mathrm{mL}$. Ten plasma samples were included in each group. Each sample was tested in triplicate.

\section{Western blotting}


Whole-tissue lysates were prepared from tissue, and the protein concentrations were measured using BCA protein assay reagent (CW0014S, CoWin Biotech Co., Inc., Beijing, China). These proteins were separated by $10 \%-15 \%$ SDS-PAGE, and then electro transferred onto polyvinylidene fluoride membranes (Millipore, Billerica, MA, USA). The membranes were blocked with $5 \%$ skim milk/0.5\% Tween-20 in TBS (TBST) for $2 \mathrm{~h}$ at room temperature. The membranes were incubated with anti-MMP-9 antibody (1:500, ABclonal Biotech Co., Ltd, Cambridge, MA, USA), anti-Caspase-3 antibody (1:1000; ABclonal Biotech Co., Ltd, Cambridge, MA, USA), anti- $\beta$-actin antibody (1:3000; CW0096, CoWin Biotech Co., Inc., Beijing, China), anti-phospho-ERK1/2 antibody (1:1000; ABclonal Biotech Co., Ltd, Cambridge, MA, USA), anti-MAPK1 antibody (1:1000; total ERK1/2; ABclonal Biotech Co., Ltd, Cambridge, MA, USA ), anti-phospho-RELAS536 antibody (1:1000; pNF-KB p65; ABclonal Biotech Co., Ltd, Cambridge, MA, USA), and anti-ADRB2 antibody (1:1000; $\beta_{2}$-AR; ABclonal Biotech Co., Ltd, Cambridge, MA, USA) overnight at $4{ }^{\circ} \mathrm{C}$. Then, the membranes were washed in TBST and incubated with horseradish peroxidase-conjugated donkey antimouse IgG (1:5000; CoWin Biotech Co., Inc., Beijing, China) (for MMP-9 and $\beta$-actin) or goat anti-rabbit IgG (1:5000; CoWin Biotech Co., Inc., Beijing, China) (for total ERK1/2, p-ERK1/2, pNF-kB p65, Caspase-3 and $\left.\beta_{2}-A R\right)$ for $2 \mathrm{~h}$ at room temperature. Immunoblotting was visualized with an ECL Western Blot Kit (1:1; CW0049M, CoWin Biotech Co., Inc., Beijing, China). The bands on the blots were scanned and analyzed by ImageJ (National Institutes of Health, Bethesda, MD, USA). The protein levels were expressed as the IOD of each band, which was normalized to the IOD of the corresponding $\beta$-actin band. Seven tissue samples were included in each group. Each sample was repeated three times.

\section{Primary culture of uterine stromal cells and drug treatment}

Primary mouse uterine stromal cells from E5 pregnant mouse uteri were isolated as described in a related study [21]. Briefly, uterine tissue from E5 mice was removed from the fat tissue, cut longitudinally, and washed with Hanks' balanced salt solution (HBSS, containing $100 \mathrm{U} / \mathrm{mL}$ penicillin and $100 \mu \mathrm{g} / \mathrm{mL}$ streptomycin). Tissues were cut into small pieces $(2-3 \mathrm{~mm}$ ) and then digested in $0.25 \%$ trypsin- $0.02 \%$ EDTA for $8 \mathrm{~min}$ at $37^{\circ} \mathrm{C}$. The tube was shaken gently to remove the endometrial epithelial cells, and the supernatant was discarded. The digested pieces were washed twice in HBSS and incubated in HBSS containing $0.1 \%$ collagenase for $40 \mathrm{~min}$ at $37^{\circ} \mathrm{C}$, and then the sample was shaken until the supernatant became turbid. At the end of digestion, the reaction was terminated with Dulbecco's modified Eagle's medium-F12 medium (DMEM-F12; HyClone, Logan, UT, USA) containing 10\% heat-inactivated fetal bovine serum (FBS), and the sample was centrifuged at $450 \mathrm{xg}$ for $10 \mathrm{~min}$. The cell pellet was passed through a nylon tissue sieve (200 nylon mesh per $2.5 \mathrm{~cm}$ ) and washed twice with serum-free DMEM-F12 medium before the initiation of primary culture. The cell concentration was adjusted, and $2 \times 10^{5}$ cells/well were seeded in 24-well cell plates. The cell plates were placed in a $5 \% \mathrm{CO}_{2}$ cell culture incubator at $37^{\circ} \mathrm{C}$, and the cells were cultured for $1 \mathrm{~h}$. The non-adhered cells were discarded, and the cells were further cultured for $24 \mathrm{~h}$.

The supernatant of ESCs that were adherent for $24 \mathrm{~h}$ was discarded and replaced with serum-free basal DMEM-F12. After starvation for $6 \mathrm{~h}$, complete DMEM-F12 containing different concentrations of drugs was added, and culture was continued for $24 \mathrm{~h}$. ISO (DL-isoproterenol hydrochloride; a nonselective 
agonist of $\beta_{2}$-AR; 15627, Sigma, USA; $0.1 \mu \mathrm{M}, 1 \mu \mathrm{M}$, or $10 \mu \mathrm{M}$ ), Butox (butoxamine hydrochloride; a selective blocker of $\beta_{2}$-AR; B1385, Sigma, USA; $0.01 \mu \mathrm{M}, 0.1 \mu \mathrm{M}$, or $1 \mu \mathrm{M}$ ), FSK (forskolin; a cAMP agonist; 66575-29-9, Tocris Bioscience, MN, USA; $0.1 \mu \mathrm{M}, 1 \mu \mathrm{M}$, or $10 \mu \mathrm{M}$ ), H-89 (a selective inhibitor of PKA; \#9844, Cell Signaling Technology, MA, USA; $0.1 \mu \mathrm{M}, 1 \mu \mathrm{M}$, or $10 \mu \mathrm{M}$ ), PD98059 (a selective inhibitor of ERK; 167869-21-8, Tocris Bioscience, MN, USA; $0.1 \mu \mathrm{M}, 1 \mu \mathrm{M}$, or $10 \mu \mathrm{M})$, PDTC (pyrrolidinedithiocarbamate ammonium; a specific blocker of NF-KB; 5108-96-3, Tocris Bioscience, MN, USA; $0.1 \mu \mathrm{M}, 1 \mu \mathrm{M}$, or $10 \mu \mathrm{M}$ ) and 0.01\% DMSO (dimethyl sulfoxide; 0231, Amresco, Ohio, USA) were added to the cells. FSK, H-89, PD98059 and PDTC were dissolved in DMSO. After the completion of culture, 5 mg/mL MTT (3-(4,5-dimethyl-2-thiazolyl)-2,5-diphenyl-2-H-tetrazolium bromide; 0793, Amresco, Ohio, USA) was added to each well to a final concentration of approximately $0.025 \mathrm{mg} / \mu \mathrm{L}$ on a clean bench. The cells were cultured in a $37^{\circ} \mathrm{C} 5 \% \mathrm{CO}_{2}$ cell incubator for $4 \mathrm{~h}, 10 \%$ SDS was added to each well to a final concentration of $5 \%$, the cells were placed in a $37^{\circ} \mathrm{C}$ incubator for $2 \mathrm{~h}$ to better dissolve the formazan, and the OD value was measured at $570 \mathrm{~nm}$ using a microplate reader.

After the optimal drug concentration was determined, cells were cultured with different drug combinations. The groups were named cells, cells $+0.01 \%$ DMSO, cells + ISO, cells + Butox + ISO, cells + FSK + ISO, cells + Butox + ISO + FSK, cells + H-89 + ISO + FSK, cells + PD98059 + ISO + FSK and cells + PDTC + ISO + FSK.

Cell proliferation was measured by the MTT assay, and the results were expressed as the stimulation index (test group OD/control group OD). After culturing for $24 \mathrm{~h}$, the cells were collected with protein lysis buffer and subjected to ultrasonic vibration. The supernatant was collected by centrifugation at $14000 \mathrm{rpm}$ for $10 \mathrm{~min}$, and the protein levels of $\beta_{2}-A R$, ERK1/2 and caspase- 3 were detected.

\section{Statistical analysis}

The data were analyzed with SPSS 18.0 (SPSS Inc., Chicago, IL) as described in a previous study [34]. To analyze the effects of restraint stress and gestational age on the experimental data, two-way analysis of variance (ANOVA) followed by Duncan's post hoc test was performed. The difference between control and stressed mice at the same gestational age was evaluated by independent sample t test. The data are expressed as the mean $\pm S D$. ${ }^{*} P \leq 0.05$ and ${ }^{\#} P \leq 0.01$ were used to denote the significance compared with the corresponding control groups. Different uppercase letters represent significant differences in the control group among E3, E5, and E7 ( $P \leq 0.05)$, and different lowercase letters represent significant differences in the stressed group among E3, E5 and E7 $(P \leq 0.05)$. To analyze the effect of the drugs on ESCs, one-way ANOVA with LSD post hoc test was performed.

\section{Results}

\section{Effects of restraint stress on body weight, blood glucose and NE in early pregnant mice}


Body weight was decreased in both control and stressed mice when water and food were withheld. Twoway analysis of weight loss before and after stress showed that changes in gestational age did not affect weight reduction $\left(F_{(2,153)}=0.852, P=0.429\right)$. However, after restraint stress treatment, the reduction in body weight was significantly increased $\left(F_{(1,153)}=189.269, P=0.000\right)$. Compared with that of the control mice, the weight reduction of E3, E5 and E7 pregnant mice increased by $82.65 \%$ (independent sample $t$ test, $P=0.000$ ), $120 \%$ (independent sample $t$ test, $P=0.000$ ) and $60.39 \%$ (independent sample $t$ test, $P=$ 0.000), respectively, after restraint stress. Compared with that of the E3 control mice, the weight reduction of pregnant mice showed a V-shaped change with increasing gestational age, decreasing by $5.28 \%$ (E3 to $E 5, P=0.913$ ) and increasing by $14.78 \%$ (E3 to $E 7, P=0.465$ ). In the three groups of stressed mice at different gestational ages, the weight reduction showed an inverted V-shape. Compared with that of the E3 stressed group, weight reduction increased by $13.99 \%$ (E3 to $E 5, P=0.030)$ and then decreased by $0.81 \%$ (E3 to $E 7, P=0.902$ ) (Fig. $2 A)$.

In general, external stress signals activate the HPA (hypothalamus-pituitary-adrenal gland) axis in the body. Then, EPI and NE are released. In addition, stress increases blood glucose levels in the body. EPI and NE convert external stimuli to biological signals in the body.

After restraint stress, the blood glucose levels of pregnant mice increased to some extent. Two-way analysis of blood glucose levels showed that changes in gestational age $\left(F_{(2,43)}=5.074, P=0.011\right)$ and restraint stress treatment $\left(F_{(1,43)}=48.415, P=0.000\right)$ caused increases in blood glucose levels. Compared with those of the control group, the blood glucose levels of E3, E5 and E7 pregnant mice increased by $26.97 \%$ (independent sample t test, $P=0.000$ ), $7.93 \%$ (independent sample $t$ test, $P=0.032$ ) and $12.51 \%$ (independent sample t test, $P=0.003$ ), respectively, after restraint stress. Compared with those of the E3 control group, the blood glucose levels increased $17.48 \%$ ( $E 3$ to $E 5, P=0.001$ ) and $15.03 \%$ (E3 to $E 7, P=$ 0.000 ) with increasing gestation age. However, there was no significant change in blood glucose levels among the three groups of stressed mice at different gestational ages (Fig. 2B).

The NE content in the plasma was measured. Both restraint stress treatment $\left(F_{(1,43)}=28.485, P=0.000\right)$ and changes in gestational age $\left(F_{(2,43)}=33.759, P=0.000\right)$ caused increases in plasma NE levels. Compared with those of the control group of the same gestational age, the NE levels of plasma on E3, E5 and $E 7$ increased by $39.49 \%$ (independent sample t test, $P=0.002$ ), $11.31 \%$ (independent sample $t$ test, $P$ $=0.029$ ) and $11.03 \%$ (independent sample t test, $P=0.049$ ), respectively, after restraint stress. Compared with that of the E3 control group, the NE content decreased by $21.29 \%$ (E3 to $E 5, P=0.002$ ) and $12.66 \%$ (E3 to $E 7, P=0.039$ ) as gestational age increased. In the stressed group, the trend of NE content in the plasma was consistent with the trend of that in the control group, which was reduced by $37.19 \%$ (E3 to $E 7, P=0.004)$ and $30.48 \%(E 3$ to $E 7, P=0.009)$ compared with that of the $E 3$ stressed group (Fig. $2 C$ ).

\section{Effect of restraint stress on $\beta_{2}$-AR levels in the pregnant mouse uterus}


Although studies have shown that the expression of $\beta_{2}-A R$ in the uterus is significantly higher than that of $\beta_{1}-A R$ and $\beta_{3}-A R$, the changes in the expression of the three receptors after restraint stress are unclear. As a receptor for NE on target organs, $\beta$-AR plays a role as a bridge for the transmission of stress signals. In this study, RT-PCR was used to detect $\beta$-AR mRNA levels in the uteri of pregnant mice. Statistical analysis of mRNA expression levels showed that the changes in the expression level of $\beta_{2}$-AR mRNA were greater than those of $\beta_{1}$-AR mRNA and $\beta_{3}$-AR mRNA after restraint stress (Fig. 3).

After restraint stress treatment, the expression of $\beta_{1}-A R$ mRNA in uterine tissue was decreased, and the content of $\beta_{1}$-AR mRNA was affected by gestational age $\left(F_{(2,48)}=63.956, P=0.000\right)$ but not by restraint stress treatment $\left(F_{(1,48)}=4.027, P=0.050\right)$. Compared with that in the uteri of control mice of the same age, the $\beta_{1}-A R$ mRNA content in the uteri of E3, E5 and E7 pregnant mice decreased by $23.61 \%$ (independent sample t test, $P=0.012$ ), $0.92 \%$ (independent sample $t$ test, $P=0.890$ ) and $4.30 \%$ (independent sample t test, $t=0.468, P=0.646$ ), respectively, after restraint stress. Compared with that in the E3 control group, the $\beta_{1}-A R$ mRNA level decreased by $44.02 \%$ ( $E 3$ to $E 5, P=0.000$ ) and increased by $26.36 \%$ ( $E 3$ to $E 7, P=0.106$ ) as the gestational age increased. The trend of $\beta_{1}-A R$ mRNA content in the stressed group was consistent with the trend in the control group. Compared with that in the E3 stressed group, the $\beta_{1}$-AR mRNA content decreased by $27.40 \%$ ( $E 3$ to $E 5, P=0.036$ ) and increased by $58.36 \%$ (E3 to $E 7, P=0.000)($ Fig. $3 A)$.

The expression of $\beta_{2}-A R$ mRNA was increased in uterine tissue after restraint stress treatment $\left(F_{(1,36)}=\right.$ 39.749, $P=0.000)$. In addition, $\beta_{2}-A R$ mRNA content was not affected by gestational age $\left(F_{(2,36)}=0.424\right.$, $P=0.658)$. Compared with that in the control mice of the same age, the $\beta_{2}-A R$ mRNA content increased by $10.60 \%$ (independent sample t test, $P=0.010$ ), $7.85 \%$ (independent sample $t$ test, $P=0.035$ ) and $20.24 \%$ (independent sample t test, $\mathrm{P}=0.000)$ after restraint stress in mice of the 3 gestational ages $(E 3, E 5$ and E7), respectively. Compared with that in the E3 control group, the $\beta_{2}-A R$ mRNA content increased by $3.24 \%$ ( $E 3$ to $E 5, P=0.413$ ) and decreased by $2.59 \%$ ( $E 3$ to $E 7, P=0.528)$ with increasing gestational age. The trend of $\beta_{2}-A R$ mRNA content in the stressed group was not consistent with the trend in the control group. Compared with that in the E3 stressed group, the $\beta_{2}$-AR mRNA content increased by $0.59 \%$ (E3 to E5, $P=$ 0.825 ) and $5.86 \%$ (E3 to E7, P = 0.046) (Fig. 3B).

After restraint stress treatment, the expression of $\beta_{3}-A R$ mRNA in uterine tissue was increased. The content of $\beta_{3}$-AR mRNA was affected by gestational age $\left(F_{(2,31)}=16.291, P=0.000\right)$ and restraint stress $\left(F_{(1,31)}=2.546, P=0.121\right)$. Compared with that in the control group of the same age, the $\beta_{3}$-AR mRNA content increased by $21.44 \%$ (independent sample $t$ test, $P=0.077$ ), $0.58 \%$ (independent sample $t$ test, $P$ $=0.958$ ) and $21.04 \%$ (independent sample t test, $P=0.428$ ) after restraint stress in mice at the 3 gestational ages (E3, E5 and E7). Compared with that in the E3 control group, the $\beta_{3}$-AR mRNA content decreased by $24.61 \%$ ( $E 3$ to $E 5, P=0.100)$ and $39.63 \%$ ( $E 3$ to $E 7, P=0.009)$ with increasing gestational age. The trend of $\beta_{3}$-AR mRNA content in the stressed group was consistent with the trend in the control 
group. Compared with that in the E3 stressed group, the $\beta_{3}-A R$ mRNA content decreased by $37.57 \%$ (E3 to $E 5, P=0.000)$ and $39.81 \%$ (E3 to $E 7, P=0.000)$ (Fig. $3 C$ ).

Next, to observe whether restraint stress has effects at the receptor protein level, detected $\beta_{2}$-AR protein by Western blotting. After restraint stress treatment, the expression of $\beta_{2}-A R$ protein in uterine tissue was increased $\left(F_{(1,28)}=9.064, P=0.005\right)$, but the content of $\beta_{2}$-AR protein was not affected by gestational age $\left(F_{(2,28)}=1.656, P=0.209\right)$. Compared with that in control mice of the same age, the $\beta_{2}-A R$ protein content decreased by $2.83 \%$ (independent sample t test, $P=0.812$ ) at $E 3$ and increased by $52.30 \%$ (independent sample $t$ test, $\mathrm{P}=0.003$ ) and $28.77 \%$ (independent sample $t$ test, $\mathrm{P}=0.042$ ) at $\mathrm{E} 5$ and $\mathrm{E} 7$ after restraint stress. There was no significant change in $\beta_{2}$-AR protein content with increasing gestation age compared with that in the E3 control group, and $\beta_{2}$-AR protein content was reduced by $25.15 \%$ (E3 to $E 5, P=0.062$ ) and $3.68 \%$ ( $E 3$ to $E 7, P=0.762$ ). The change in $\beta_{2}-A R$ protein content in the stressed group was also not significant. Compared with that in the E3 stressed group, the $\beta_{2}-A R$ protein content increased by $17.19 \%$ ( $E 3$ to $E 5, P=0.322$ ) and $27.44 \%$ ( $E 3$ to $E 7, P=0.216$ ) (Fig. 4).

To study the signaling pathway downstream of $\beta_{2}-A R$, we determined the immunohistochemical localization of $\beta_{2}$-AR to select cell types for subsequent experiments. $\beta_{2}-A R$ immunohistochemical staining showed that $\beta_{2}$-AR positive cells (yellow) were not only expressed in the longitudinal muscle layer and vascular layer of the uterus but also in the endometrium. At E3 and E5, $\beta_{2}$-AR expression was found in glandular epithelial cells, luminal epithelial cells and endometrial cells. At E7, a large amount of $\beta_{2}$-AR was located in decidual cells (Fig. 5).

\section{Activation of the apoptosis pathway by restraint stress}

To investigate whether the microenvironment of the uterus in early pregnancy is disordered, we examined uterine cell apoptosis and oxidative stress-related proteins. We found that the levels of apoptosis and antioxidants in the uterus were disrupted by restraint stress.

MMP-9 plays an important role in mouse embryo implantation and prevents the release of cytochrome c from blocking the occurrence of apoptosis. If its expression is disturbed, the microenvironment of the uterus is destroyed. MMP-9 protein expression in the uterus was affected by gestational age $\left(F_{(2,18)}=\right.$ 52.718, $P=0.000)$ and restraint stress treatment $\left(F_{(1,18)}=93.987, P=0.000\right)$. Compared with that in the uteri of control mice of the same age, the MMP-9 protein content in the uteri of E3, E5 and E7 pregnant mice decreased by $39.44 \%$ (independent sample $t$ test, $t=3.412, P=0.028$ ), $63.45 \%$ (independent sample $t$ test, $P=0.000$ ) and $24.67 \%$ (independent sample $t$ test, $P=0.004$ ), respectively, after restraint stress. Compared with that in the E3 control group, the MMP-9 protein content increased by $181.50 \%$ (E3 to E5, $P$ $=0.000$ ) and $90.85 \%$ (E3 to $E 7, P=0.000)$ as gestational age increased. The trend of MMP-9 protein content in the stress group was not consistent with the trend in the control group. Compared with that in the E3 stressed group, the MMP-9 protein content increased by $70.10 \%$ (E3 to $E 5, P=0.014$ ) and $137.46 \%$ (E3 to $E 7, P=0.000)$ (Fig. 6A). 
Caspase-3 is an effector of apoptosis, and changes in its expression affect changes in the microenvironment of the uterus, disturbing the balance of cell proliferation and apoptosis in the uterus. Caspase-3 protein content in uterine tissue was not affected by gestational age $\left(F_{(2,53)}=2.971, P=\right.$ $0.060)$ and was only affected by restraint stress treatment $\left(F_{(1,53)}=26.682, P=0.000\right)$. Compared with that in the uteri of control mice of the same age, the Caspase-3 protein content in the uteri of E3, E5 and E7 pregnant mice was increased by $44.69 \%$ ( $E 3$, independent sample $t$ test, $P=0.012), 42.92 \%$ ( $E 5$, independent sample t test, $P=0.000$ ) and $30.10 \%(E 7$, independent sample t test, $P=0.019$ ), respectively, after restraint stress. Compared with that in the E3 control group, the Caspase-3 protein content increased by $20.77 \%$ ( $E 3$ to $E 5, P=0.114$ ) and $27.69 \%$ ( $E 3$ to $E 7, P=0.061$ ) as the gestational age increased. The trend of Caspase-3 protein content in the stress group was not consistent with the trend in the control group. Compared with that in the E3 stressed group, the Caspase-3 protein content increased by $19.10 \%$ (E3 to $E 5, P=0.132$ ) and $14.59 \%$ (E3 to $E 7, P=0.244)$ (Fig. $6 B$ ).

Oxidative stress during pregnancy can trigger disorder of the immune microenvironment of the uterus, and oxidative stress can induce the activation of NF-KB by activating ERK, thereby promoting inflammation; additionally, the activation of ERK and NF-KB can promote the occurrence of cell apoptosis.

The level of pERK1/2 protein in uterine tissue was not affected by gestational age $\left(F_{(2,18)}=1.055, P=\right.$ $0.369)$ and was only affected by restraint stress treatment $\left(F_{(1,18)}=19.922, P=0.000\right)$. Compared with that in the uteri of control mice of the same age, the pERK1/2 level in the uteri of E3, E5 and E7 pregnant mice was increased by $52.30 \%$ (independent sample $t$ test, $P=0.025$ ), 38.85\% (independent sample t test, $P=0.049$ ) and $44.84 \%$ (independent sample t test, $P=0.030$ ), respectively, after restraint stress.

Compared with that in the E3 control group, the pERK $1 / 2$ protein content increased by $20.49 \%$ (E3 to E5, $P=0.223$ ) and $17.28 \%$ ( $E 3$ to $E 7, P=0.300$ ) as the gestational age increased. The trend of $p E R K 1 / 2$ protein content in the stressed group was not consistent with the trend in the control group. Compared with that in the E3 stressed group, the pERK1/2 content increased by $10.06 \%$ (E3 to $E 5, P=0.496$ ) and $11.69 \%$ (E3 to $E 7, P=0.432$ ) (Fig. 6C).

The pNF-kB p65 protein content in uterine tissue was affected by gestational age $\left(F_{(2,52)}=6.758, P=\right.$ $0.002)$ and restraint stress treatment $\left(F_{(1,52)}=42.177, P=0.000\right)$. Compared with that in the uteri of control mice of the same age, the pNF-KB p65 protein content in the uteri of E3, E5 and E7 pregnant mice was increased by $74.47 \%$ (independent sample $t$ test, $P=0.001$ ), $56.12 \%$ (independent sample $t$ test, $P=$ 0.001 ) and $54.38 \%$ (independent sample t test, $P=0.019$ ), respectively, after restraint stress. Compared with that in the E3 control group, the pNF-KB p65 protein content increased by $4.83 \%$ (E3 to E5, $P=0.994$ ) and $42.41 \%$ ( $E 3$ to $E 7, P=0.117$ ) with increasing gestational age. The trend of pNF-kB p65 protein content in the stressed group was not consistent with the trend in the control group. Compared with that in the E3 stressed group, the pNF-KB p65 protein content decreased by $6.51 \%$ (E3 to $E 5, P=0.554$ ) and increased by $25.64 \%$ (E3 to $E 7, P=0.039$ ) (Fig. 6D).

\section{Effect of $\beta_{2}$-AR activation on the proliferative activity of ESCs}


In subsequent studies, protein was extracted from ESCs for Western blotting detection. The result showed that $\beta_{2}$-AR was present in ESCs, which provided a reliable theoretical basis for adding drug to cells in vitro (Fig. 7A).

To further investigate the $\beta_{2}$-AR signaling pathway, appropriate concentrations of ISO, FSK, butoxamine, $\mathrm{H}-89$, PD98059 and PDTC were determined based on their effect on cell viability. The concentrations of ISO, FSK, butoxamine, H-89, PD98059 and PDTC were $10 \mu \mathrm{M}, 1 \mu \mathrm{M}, 1 \mu \mathrm{M}, 1 \mu \mathrm{M}, 1 \mu \mathrm{M}$ and $1 \mu \mathrm{M}$, respectively (Fig. 7B-G).

As an organic solvent, DMSO was used to dissolve FSK, H-89, PD98059 and PDTC in this study. Therefore, a DMSO group was established to determine whether $0.01 \%$ DMSO in cell suspension affects cell proliferation. Compared with that of the blank control group, cell proliferation of a cell suspension was not affected after incubation in $0.01 \%$ DMSO for $24 \mathrm{~h}(P=0.106)$. This result indicated that dissolving the drug in medium containing $0.01 \%$ DMSO did not interfere with the effect of the drugs on the cells (Fig. 7H).

Compared with that of control cells, proliferation was significantly reduced by $38.60 \%(P=0.000)$ in cells treated with $10 \mu \mathrm{M}$ ISO in vitro. However, compared with ISO, the addition of the $\beta_{2}$-AR blocker butoxamine reversed the antiproliferative effect of ISO, resulting in a significant $43.95 \%$ increase $(P=$ $0.000)$ in cell proliferation. It was again demonstrated that $\beta_{2}$-AR plays a major role in the proliferation of ESCs (Fig. 7H).

In the drug concentration exploration test, it was found that FSK and ISO showed a synergistic antiproliferative effect. After the addition the $\beta_{2}$-AR blocker butoxamine, FSK and ISO were added together to the cultured cells for $24 \mathrm{~h}$. Compared with that of the control group, proliferative activity was still reduced by $36.36 \%(P=0.000)$, and the difference was not significant compared with the ISO-treated group $(P=0.720)$. However, compared with ISO, the addition of the PKA inhibitor $\mathrm{H}-89$ significantly increased cell proliferative activity by $37.55 \%(P=0.000)$. This result indicated that the activation of $\beta_{2}-A R$ inhibited the proliferation of ESCs mainly through the cAMP/PKA pathway (Fig. $7 \mathrm{H})$.

The MEK inhibitor PD98059 specifically blocks the activation of ERK. Compared with ISO, the addition of the MEK inhibitor PD98059 significantly increased cell proliferation by $36.31 \%(P=0.001)$. After treatment with PDTC, a specific blocker of NF-KB, for $24 \mathrm{~h}$, ISO and FSK were added to the cells. The proliferative activity of ESCs did not decrease. Compared with ISO, the addition of PDTC increased the cell proliferation by $40.80 \%(P=0.000)$. This result indicated that the activation of $\beta_{2}$-AR inhibited the proliferation of ESCs mainly by activating downstream ERK/MAPK signaling through the CAMP/PKA pathway and inducing NF-KB activation, thereby initiating apoptosis (Fig. $7 \mathrm{H})$.

\section{Effect of $\beta_{2}$-AR activation on intracellular signal changes in endometrial stromal cells (ESCs) from pregnant mice}


Uterine ESCs treated with different drugs were collected, and the expression of pERK $1 / 2$ in the cells was detected by the WB method. The DMSO-treated group exhibited no significant change in the expression of pERK1/2 compared with that of the blank control group $(P=0.059)$. The addition of the $\beta_{2}-A R$ agonist ISO in vitro significantly increased the expression of pERK $1 / 2$ by $37.84 \%(P=0.005)$ compared with that in the group. This indicated that ISO involved the activation of the pERK1/2 protein, which is involved in cell proliferation-induced apoptosis. However, after the addition of the adenylyl cyclase agonist FSK, the expression of pERK $1 / 2$ in the cells was significantly increased by $58.03 \%(P=0.000)$ compared with that in the control group, and the difference was not significant compared with the ISO-treated group $(\mathrm{P}=$ 0.085). The addition of the PKA inhibitor $\mathrm{H}-89$ reversed the expression of pERK1/2. Compared with that in the ISO-treated group, the expression of pERK $1 / 2$ was significantly reduced by $21.83 \%(P=0.007)$. However, after treatment with the $\beta_{2}$-AR blocker butoxamine for $30 \mathrm{~min}$, FSK and ISO were added to the cells, and the cells were cultured for $24 \mathrm{~h}$. Compared with that in the control group, the expression of pERK1/2 was significantly increased by $54.71 \%(P=0.000)$. The difference was not significant compared with the ISO-treated group $(P=0.133)$. This result indicated that the stimulation of $\beta_{2}$-AR inhibited cell proliferation and induced apoptosis of ESCs mainly through the CAMP/PKA pathway. The MEK inhibitor PD98059 specifically blocked the activation of ERK. Compared with ISO, the addition of PD98059 significantly reduced the expression of pERK $1 / 2$ in cells by $70.08 \%(P=0.000)$. The cells were treated with PDTC for $24 \mathrm{~h}$, and then ISO and FSK were added; the expression of pERK1/2 did not increase in the cells. Compared with ISO, the addition of PDTC significantly decreased the expression of pERK $1 / 2$ in the cells by $61.04 \%(P=0.000)$ (Fig. $8 \mathrm{~A})$.

Caspase-3, a member of the Caspase family, plays an important role in the activation of apoptosis, which links mitochondria inside the cell with the external death receptor. Uterine ESCs treated with different drugs were collected, and the expression of Caspase- 3 in the cells was detected by the WB method. The DMSO-treated group exhibited no significant change in the expression of Caspase-3 compared with that in the blank control group $(P=1.000)$. The addition of the $\beta_{2}$-AR agonist ISO in vitro significantly increased the expression of Caspase-3, and the expression of Caspase- 3 was significantly increased by $119 \%(P=0.021)$ compared with that in the control group. These results indicated that ISO induced the activation of Caspase-3 protein during ESC apoptosis. However, after the addition of the adenylyl cyclase agonist FSK, there was no significant change in the expression of Caspase-3 in the cells compared with that in the ISO-treated group $(P=0.051)$. The addition of the PKA inhibitor $\mathrm{H}-89$ reversed the expression of Caspase-3 induced by ISO and FSK. Compared with that in the ISO-treated group, the expression of Caspase-3 was significantly reduced by $68.51 \%(P=0.004)$. After the cells were treated with the $\beta_{2}-A R$ blocker butoxamine for $30 \mathrm{~min}$, Iso was applied to the cells for $24 \mathrm{~h}$. Compared with that in the ISOtreated group, the expression of Caspase- 3 was significantly decreased by $77.94 \%(P=0.001)$. The process of $\beta_{2}$-AR-induced apoptosis in ESCs is mainly achieved through the CAMP/PKA pathway. The MEK inhibitor PD98059 specifically blocked the activation of ERK. Compared with ISO, the addition of the MEK inhibitor PD98059 significantly reduced the expression of Caspase-3 in cells by $52.15 \%(P=0.017)$. The cells were treated with PDTC for $24 \mathrm{~h}$, and then ISO and FSK were added; the expression of Caspase3 did not increase in these cells compared with ISO-treated cells. The addition of PDTC significantly 
decreased the expression of Caspase-3 in the cells by $74.79 \%(P=0.002)$. In conclusion, the activation of $\beta_{2}$-AR promoted the apoptosis of ESCs mainly by activating downstream ERK/MAPK signaling through the CAMP/PKA pathway and inducing NF-KB activation, thereby initiating apoptosis (Fig. 8B).

\section{Discussion}

According to data released by the World Health Organization, approximately $17 \%$ of individuals worldwide suffer from mental illness, and $76-85 \%$ of patients are in urgent need of intervention from a professional psychiatrist. More than 300 million people depression, more than 260 million people suffer from anxiety disorders, 60 million people have bipolar disorder, 21 million people have schizophrenia, and 47.5 million people suffer from dementia. The annual economic loss caused by depression and anxiety alone amount to $\$ 100$ billion. In 2020 , mental illness will account for a quarter of the total burden of disease in the world. In a recent study, the cumulative psychosocial stress (CPS) score, which encompasses acute stressors (such as negative events) and chronic stressors (such as work, work-family spillover, financial discrimination, relationships and neighborhood), was created. The study showed that socioeconomic status (income and education) and psychological status (depression and anxiety) are most likely to cause a rise in mental illness and a higher CPS score [35]. Psychological stress is associated with an increased risk of cardiovascular disease [36]. Clinically, work stress leads to an increase in the incidence of heart disease and an increase in mortality. Men have a higher incidence of heart disease than women [37]. Meanwhile, $\beta$-AR is an important target for many researchers for the study of heart disease and its treatment $[38,39]$. However, a meta-analysis of representative national samples corroborated that women are approximately twice as likely as men to be diagnosed with depression [40]. In psychological diseases, $\beta$-AR is mainly involved in memory and behavior [41, 42]. However, $\beta-A R$, as a treatment target for a series of stress-related diseases, has rarely been studied in other organs. In women, reproductive diseases are a critical aspect of psychological stress. A study showed that as many as $19.2 \%$ (7.1\%) of women have a depressive episode (major depressive episode) during early pregnancy [43]. Some human and animal studies have indicated that in utero exposure to stress may contribute to poor perinatal outcomes [44]. Therefore, the uterus may be an important organ for studying reproductive stress exposure as a form of psychological stress. Additionally, in the present study, we found that restraint stress affected the balance between oxidation and antioxidation [10], as well as the balance between proliferation and apoptosis, under restraint stress in early pregnancy [21]. Recently, psychological stress has attracted worldwide attention. However, the effects of chronic psychosocial maternal stress (CMS) during early gestation on the stress signaling mechanism are unclear in many women [45]. In this article, we speculated that the mechanism by which restraint stress affects the uterine microenvironment in early pregnant mice may be the $\beta_{2}-\mathrm{AR}$ signaling pathway.

\section{Restraint stress disturbs the developmental and endocrine environment in pregnant mice}


Stress is a way that the body communicates with the outside world, and this occurs mainly through two pathways. The hypothalamic-pituitary-adrenal axis is a pivotal component of the response of organisms to stressful challenges, and the dysfunction of this neuroendocrine axis is associated with a variety of physiological and psychological pathologies [46]. The sympathetic-adrenal medullary system (SAS), which releases the catecholamine norepinephrine to transmit sympathetic signals to peripheral organs, is the other pathway. Both methods affect the change in hormones induced by stress. Additionally, a study reported anatomical and physiological characteristics of the locus coeruleus (LC)-norepinephrine (NE) (LC-NE) system that give it the potential to be a major stress response system. It can process cardiovascular information and in turn can impact cardiovascular function [47]. A study of schizophrenia and PTSD demonstrated that the corticotropin-releasing factor (CRF) and NE systems, both of which are activated by stress, are the most widely implicated systems in stress-induced psychopathology [48]. In fact, the impact of stress on body function depends on the nature, duration, and intensity of the stressor [49]. For example, psychosocial stress leads to transient increases in heart rate and blood pressure, and it has acute effects. However, people who experience "permanent stress" at work or at home are more likely than normal people to have a myocardial infarction [50]. Physiological dysregulation due to chronic stress has been proposed as a possible mechanism in adverse pregnancy outcomes [51]. In our work, we found that NE levels decreased as the gestational age increased. After restraint stress, NE concentrations at E3, E5 and E7 were significantly increased, indicating that restraint stress causes disorder of NE in early pregnancy. Our data are in agreement with previous reports, suggesting a crucial role for NE in restraint stress during pregnancy. Restraint stress causes the stress signal in the body to be activated, causing some pregnancy disorders. For example, increased levels of plasma NE are sustained in women with previous preeclampsia, which may contribute to the increased risk for cardiovascular disease in these women [52]. The activation of noradrenergic receptors increases the risk of pregnancy-induced hypertension [53]. A study reported that chronic restraint stress triggers dopaminergic (DA) and noradrenergic neurodegeneration by increasing oxidative stress, causing Parkinson's disease (PD) [54]. The catecholaminergic system has been implicated in the regulation of blood glucose levels [55]. Additionally, gluconeogenesis is usually enhanced by glucocorticoids and then increases blood glucose levels [56]. In our previous study, CORT was increased in early pregnancy under restraint stress [10]. Additionally, in this work, blood glucose levels were increased under the restraint stress at three gestational ages, suggesting a high risk for gestational diabetes. Restraint stress results in a decrease in body weight due to a massive consumption of energy and a continuous reduction in body temperature [57]. Therefore, diabetes may gradually reduce body weight and maintain normal functions of the body [58]. In our study, the reduction in body weight was increased early after restraint stress. All in all, we speculate that the SAS and HPA are activated and then release NE to increase blood glucose levels. Furthermore, body weight decreases, possibly causing embryonic growth retardation.

\section{Restraint stress disturbs adaptive changes in proliferation and apoptosis in the uteri of pregnant mice}


Increasing evidence has indicated that excessive ROS result in calcium overload, protein and lipid peroxidation, cytokine upregulation, and DNA and caspase activation $[59,60]$. Based on the information presented in the introduction, we know that the balance of oxidation/antioxidation and proliferation/apoptosis is important during early pregnancy. However, restraint stress was shown to disrupt the between oxidative/antioxidative balance [10] and the proliferation/apoptosis balance [21] in our previous studies (Fig. 9). An increase in ROS and an imbalance of the antioxidant system contributes to apoptosis in oocytes [61]. In this study, the protein levels of Caspase-3 were significantly increased under restraint stress during early pregnancy at three gestational ages (Fig. 9). An increase in Caspase-3 inhibits PARP1, a death substrate of Caspase-3. A decrease in PARP1 during blastocyst implantation results in a decrease in the number of embryos [62]. The abovementioned findings suggest that an increase in Caspase-3 is harmful for embryo implantation. In addition, MMP-9 deficiency increases apoptosis levels [63]. Decreased expression of MMP-9 results in cytochrome c release from mitochondria into the cytosol to induce cell apoptosis [64]. In our study, the protein levels of MMP-9 were obviously decreased under restraint stress during early pregnancy at the three gestational ages. Meanwhile, under control conditions, we found that the protein levels of MMP-9 were higher on E5 than on the other two gestational days (Fig. 9). We speculate that MMP-9 is not only involved in apoptosis but is also important for implantation. MMP-9 is a major contributor to normal implantation and plays a role in embryonic trophoblast development. A study showed that pregnant MMP-9-null mice exhibit clinical symptoms of preeclampsia [65]. All in all, restraint stress may decrease the expression of MMP-9, which promotes the release of cytochrome $c$ and then induces apoptosis (Fig. 9).

In our previous study, restraint stress was shown to cause local immune regulation disorder in the uterus. It promotes the release of the Th1 inflammatory cytokine IL-2, which is not conducive to embryo implantation. Meanwhile, restraint stress causes a decrease in antioxidative ability, which is involved in oxidative stress [10]. Additionally, a study showed that CD4(+) T cells mediate oxidative stress to cause hypertension during preeclampsia [66]. A study demonstrated that bisphenol-A (BPA), a material that can induce oxidative stress and inflammation, increases the levels of IL- 6 in the circulating plasma throughout pregnancy and increases maternal biomarkers of oxidative stress, including indices of oxidative DNA and lipid damage [67]. Therefore, restraint stress is associated with inflammation. Additionally, in our study, the protein levels of pNF-KB p65 were increased under restraint stress during early pregnancy on E3, E5 and E7 (Fig. 9). pNF-KB p65 may promote inflammation, which is consistent with our previous studies, and an increase in NF-KB leads to a range of inflammation-related diseases, including acute lymphoblastic leukemia [68], colorectal cancer [69], and auto-inflammatory diseases [70]. The release of TNF- $a$ (tumor necrosis factor-alpha) is affected by increases in NF-KB and results in endothelial cell dysfunction, leading to preeclampsia [71]. In addition, in one study, HSP70 was shown to activate NF-KB in an ERK1/2-dependent manner, then leading to the expression of cytokines [72]. Additionally, a study showed that fenvalerate activates the ERK/NF-KB pathway, inducing apoptosis in the liver [73]. Thus, we speculate that ERK1/2 may be involved in restraint stress. In our study, the protein levels of ERK $1 / 2$ were detected. The results showed that the protein expression of ERK $1 / 2$ was increased significantly under restraint stress during early pregnancy. One study showed that ERK $1 / 2$ participates in 
depression in offspring caused by prenatal stress (restraint stress) [74]. In summary, uterine development may be affected by ERK1/2/NF-KB under restraint stress during early pregnancy (Fig. 9). Based on this study, we asked whether ERK/NF-KB affects uterine development by participating in the process of apoptosis. We then explored the mechanism in ESCs.

\section{$\beta_{2}$-AR plays an important role in the effect of restraint stress on the uterine microenvironment in pregnant mice}

Stress activates the HPA and the SAS, which induce the release of glucocorticoids from the adrenal cortex and the catecholamines EPI and NE from the adrenal medulla and sympathetic nerve termini [49]. NE acts on adrenergic receptors, including a-ARs $\left(a_{1} A, a_{1} B, a_{1} D, a_{2} A, a_{2} B\right.$, and $\left.a_{2} C\right)$ and $\beta-A R s\left(\beta_{1}, \beta_{2}\right.$, and $\left.\beta_{3}\right)$. $A$ study showed that the expression of $\beta_{2}$-AR is higher than that of $\beta$-ARs in the mouse uterus [19]. In our study, $\beta$-AR subtypes were detected by RT-PCR. The results showed that only $\beta_{2}-A R$ was significantly increased under restraint stress (Fig. 9). This demonstrates that $\beta_{2}$-AR plays an important role in the mouse uterus under restraint stress. Additionally, $\beta_{2}$-AR is a $G$ protein-coupled receptor. It promotes or inhibits the expression of cAMP by combining with Gs or Gi [75]. Acute $\beta$-AR stimulation rapidly generates ROS, which can modulate cellular and functional responses in the heart in the short-term [76]. However, a study found that chronic isoproterenol (ISO) stimulation in vivo induces ROS-dependent myocardial fibrosis. In other words, long-term $\beta$-AR-mediated oxidative stress has detrimental effects [77].

Therefore, our study used $\beta_{2}-A R$ as a starting point to study signaling pathways. In this work, we also measured the protein levels of $\beta_{2}-A R$, which were obviously increased on E5 and E7 under restraint stress. This implies that $\beta_{2}-A R$ plays a role during implantation. $A$ study showed that $\beta_{2}-A R$ is only expressed in cells incubated with embryonic culture media from embryos [78]. Our work is consistent with this related study. Next, we determined the immunohistochemical localization of $\beta_{2}-A R$ in the uterus. $\beta_{2}-A R$ was expressed not only in the longitudinal muscle and the vascular layers of the uterus but also in the endometrium (glandular epithelial cells, luminal epithelial cells and endometrial cells) in E3 and E5. On E7, a large amount of $\beta_{2}-A R$ was present in decidual cells. Therefore, ESCs were used to explore the $\beta_{2}-A R$ signaling pathway. Additionally, the mechanism by which $\beta_{2}$-AR is regulated in ESCs is unclear.

\section{The cAMP/PKA pathway mediates the effects of $\beta_{2}$-AR on the uteri of pregnant mice}

As a G-protein coupled receptor, $\beta_{2}$-AR plays an important role in transmitting external stress signals, and it is very important to study its intracellular signaling pathway. Its activation is critical in the processes of apoptosis and inflammation. In addition, $\beta_{2}$-AR induces a significant increase in implantation [78], 
implying that $\beta_{2}$-AR plays an important role in the intrauterine microenvironment. Moreover, uterine cell proliferation and downregulation of $\beta_{2}$-AR in the uterus are induced by obesity [79].

A review determined that NE can stimulate the expression of $\beta_{2}-A R$ and can be inhibited by $\beta_{2}-A R$ antagonists. When NE-stimulated apoptosis is mimicked by both ISO and FSK, its effect can be inhibited by $\mathrm{H} 89$, an inhibitor of PKA, suggesting that this process involves PKA [80]. We believe that restraint stress induces the $\beta_{2}$-AR/cAMP pathway to transmit signals to cells and induce cell apoptosis. As an intracellular second messenger, cAMP activates the major downstream protein PKA. Meanwhile, PKA is involved in the mechanism of $\beta_{2}$-AR/cAMP-induced apoptosis. A study showed that ISO activates $\beta_{2}-A R-$ and NF-KB-dependent mechanisms, inducing the myocardial and systemic elaboration of IL-18 [81]. $\beta_{2}-A R$ activation results in embryonic proliferation inhibition and pluripotent stem cell cycle arrest. This effect selectively depends on $\beta_{2}$-AR signaling, which involves the regulation of AKT (protein kinase B), ERK and Cyclin E [82]. Therefore, in our study, DL-isoproterenol hydrochloride (ISO, a nonselective agonist of $\beta_{2^{-}}$ $A R$ ), butoxamine hydrochloride (Butox, a selective blocker of $\beta_{2}-A R$ ), forskolin (FSK, a cAMP agonist), $\mathrm{H}-$ 89 (a selective inhibitor of PKA), PD98059 (a selective inhibitor of ERK) and pyrrolidinedithiocarbamate ammonium (PDTC, a specific blocker of NF-KB) were used to study the mechanism. Each drug was tested at different concentrations. Ultimately, we chose $10 \mu \mathrm{M}, 1 \mu \mathrm{M}, 1 \mu \mathrm{M}, 1 \mu \mathrm{M}, 1 \mu \mathrm{M}$, and $1 \mu \mathrm{M}$ as the concentrations of ISO, Butox, FSK, H-89, PD98059 and PDTC, respectively.

In our study, the stimulation index of uterus ESCs was significantly increased when $\beta_{2}$-AR was activated by ISO. There was no change in the ISO + FSK-treated group compared with the ISO-treated group (Fig. 9). This demonstrates that $\beta_{2}$-AR-cAMP is activated to regulate downstream signals. A previous study also proved that excessive NE can activate $\beta_{2}-A R / c A M P$ in rat peritoneal macrophages [83]. However, the mechanism of the effects of $\beta_{2}-A R / c A M P$ in the uterus during early pregnancy is unclear. Next, Butox was added before ISO, or both of the drugs were added together. The stimulation index of uterus ESCs was obviously decreased compared with that in the ISO-treated group, and the ISO + FSK-treated group exhibited no change compared with the ISO-treated group. Furthermore, the activation of $\beta_{2}$-AR/cAMP was explained. Similarly, Caspase-3 was significantly activated in the ISO-treated group, and the change observed in the ISO + FSK-treated group was the same as that observed in the ISO-treated group. However, compared to ISO, Butox inhibited Caspase-3, but there was no difference compared to ISO + FSK (Fig. 9). The direct activation of PKA by cAMP or by expression of the PKA catalytic subunit leads to the activation of Caspase-8 and the induction of endothelial cell apoptosis [84]. In addition, a study showed that a cAMP agonist and PKA induce neuronal apoptosis in mice with Alzheimer's disease (AD) and type 2 diabetes (T2D) and that $\mathrm{H}-89$ treatment reverses apoptosis [85]. However, a study reported AKAP121/PKA as a new molecular target that stabilizes mitochondrial networks and mitochondrial function and elicits antioxidant responses by phosphorylating Drp1 [86]. Meanwhile, in our study, compared with ISO, H-89 also prevented apoptosis and did not change the stimulation index. It was further demonstrated that in ESCs, the inhibition of proliferation and apoptosis by $\beta_{2}$-AR activation was achieved through the cAMP/PKA pathway. 
Meanwhile, pERK1/2 was obviously increased in the ISO-treated group and the ISO + FSK-treated group. However, Butox prevented the increased expression of pERK1/2. A PKA inhibitor weakened the pERK1/2 levels. These results demonstrate that ERK is involved in apoptosis and is regulated by PKA (Fig. 9). However, in prostate cancer cells, PAGE4 (prostate-associated gene 4) promotes cell survival by regulating MAPK, JNK (c-Jun N-terminal kinase) and c-jun and increasing the phosphorylation of ERK1/2 [87]. During preeclampsia, inositol second messengers are highly expressed and promote significant MAPK/ERK phosphorylation [88]. Additionally, a study indicated that $\beta_{2}$-AR activation induces microglial PHOX activation and DA neurotoxicity and that the ERK-dependent/PKA-independent pathway is involved in this process [89]. Therefore, PKA-induced apoptosis may occur via ERK phosphorylation. This mechanism needs to be further studied.

Therefore, we wanted to determine whether ERK promotes apoptosis. When ERK was inhibited by PD98059, the stimulation index was significantly increased and Caspase-3 was obviously decreased compared with the levels observed in the ISO-treated group. Thus, ERK activation induced apoptosis via the PKA pathway (Fig. 9). A study showed that oxidative stress-induced neuronal apoptosis is mainly mediated by the NF-KB, JNK, and ERK pathways [30]. When NF-KB p65 was inhibited by PDTC, the change was the same as that observed when ERK was suppressed. Meanwhile, the expression of pERK $1 / 2$ did not change after NF-KB p65 was inhibited. Moreover, in our previous study, restraint stress was shown to induce inflammation during early pregnancy (Fig. 9) [10]. Furthermore, the ERK/NF-KB pathway is activated in the lungs of asthmatic mice, inducing an imbalance in Th1/Th2 and Treg/Th17 lymphocytes and decreasing the levels of IL-4 and IL-17 [90].

In summary, ERK is activated by the $\beta_{2}-A R / c A M P / P K A$ pathway, thus promoting cell apoptosis. Combined with our previous studies, these findings suggest that ERK may induce inflammation by activating NF-KB p65 (Fig. 9).

\section{Conclusion}

All in all, in vivo tests showed that restraint stress leads to an increase in NE and blood glucose levels and a slow increase in weight. The body receives exogenous stress signals, which leads to an increase in $\beta_{2}-$ AR and the transmission of signals to cells, resulting in an elevation of Caspase- 3 and phosphorylated ERK and ultimately in apoptosis. Meanwhile, pNF-KB p65 is also elevated, confirming that restraint stress induces the onset of inflammation. In vitro experiments showed that ERK is activated by $\beta_{2}{ }^{-}$ AR/cAMP/PKA signaling, which then promotes the elevation of Caspase-3, promotes apoptosis and inhibits proliferation. At the same time, ERK may promote the elevation of NF-KB p65, thereby promoting the occurrence of inflammation.

\section{Abbreviations}

ELISA: Enzyme-linked immunosorbent assay; AR: Adrenergic receptor; $\beta_{2}$-AR: $\beta_{2}$-Adrenergic receptor; cAMP: Cyclic adenosine monophosphate; PKA: Protein kinase A; NF-кB: Nuclear factor-кB; MMP9: Matrix 
metalloprotein 9; ERK1/2: Extracellular regulated protein kinases; OCD: Obsessive-compulsive disorder; PTSD: Posttraumatic stress disorder; T-SOD: Total superoxide dismutase; ROS: Reactive oxygen species; MDA: Malondialdehyde; CORT: Corticosterone; NE: Norepinephrine; AC: Adenylyl cyclase; ClH: Chronic intermittent hypoxia; MAPK: Mitogen-activated protein kinase; RAGE: Receptor for advanced glycation end-products; CPS: Cumulative psychosocial stress; CMS: Chronic psychosocial maternal stress; SAS: Sympathetic-adrenal medullary system; LC-NE: Locus coeruleus-norepinephrine; CRF: Corticotropinreleasing factor; DA: Dopaminergic; PD: Parkinson's disease; HPA: Hypothalamus-pituitary-adrenal gland; BPA: Bisphenol-A; TNF-a: Tumor necrosis factor-alpha; ESCs: Endometrial stromal cells; ISO: Isoproterenol; JNK: c-Jun N-terminal kinase; PAGE4: Prostate-associated gene 4.

\section{References}

1.Holmes, E. A., Craske, M. G. Graybiel, A. M. Psychological treatments: A call for mental-health science. Nature. 2014;511ه7509®: 287-9.

2.Battle, D. E. Diagnostic and Statistical Manual of Mental Disorders (DSM). CoDAS. 2013;25®2®: 191-2.

3.Marquesim, N. A., Cavassini, A. C., Morceli, G., Magalhaes, C. G., Rudge, M. V., Calderon Ide, M. et al. Depression and anxiety in pregnant women with diabetes or mild hyperglycemia. Arch Gynecol Obstet. 2016;293囚4囚: 833-7.

4.Blohm, F., Friden, B. Milsom, I. A prospective longitudinal population-based study of clinical miscarriage in an urban Swedish population. BJOG. 2008;115囚2囚: 176-82; discussion 183.

5.Sominsky, L., Hodgson, D. M., McLaughlin, E. A., Smith, R., Wall, H. M. Spencer, S. J. Linking Stress and Infertility: A Novel Role for Ghrelin. Endocr Rev. 2017;38®5®: 432-67.

6.Janssen, H. J., Cuisinier, M. C., de Graauw, K. P. Hoogduin, K. A. A prospective study of risk factors predicting grief intensity following pregnancy loss. Arch Gen Psychiatry. 1997;54囚1囚: 56-61.

7.Dunkel Schetter, C. Tanner, L. Anxiety, depression and stress in pregnancy: implications for mothers, children, research, and practice. Curr Opin Psychiatry. 2012;25邓2邓: 141-8.

8.Burton, G. J. Jauniaux, E. Oxidative stress. BEST PRACT RES CL OB. 2011;25『3囚: 287-99.

9.Patel, S., Sharma, D., Kalia, K. Tiwari, V. Crosstalk between endoplasmic reticulum stress and oxidative stress in schizophrenia: The dawn of new therapeutic approaches. Neurosci Biobehav Rev. 2017;83: 589603.

10.Liu, G., Dong, Y., Wang, Z., Cao, J. Chen, Y. Restraint stress alters immune parameters and induces oxidative stress in the mouse uterus during embryo implantation. Stress. 2014;17『6『: 494-503.

11.Eick, S. M., Barrett, E. S., van 't Erve, T. J., Nguyen, R. H. N., Bush, N. R., Milne, G. et al. Association between prenatal psychological stress and oxidative stress during pregnancy. Paediatr Perinat Epidemiol. 
12.Dong, L., Wang, S., Li, Y., Zhao, Z., Shen, Y., Liu, L. et al. RU486 Reverses Emotional Disorders by Influencing Astrocytes and Endoplasmic Reticulum Stress in Chronic Restraint Stress Challenged Rats. Cell Physiol Biochem. 2017;42®3囚: 1098-108.

13.Spiers, J. G., Chen, H. J., Sernia, C. Lavidis, N. A. Activation of the hypothalamic-pituitary-adrenal stress axis induces cellular oxidative stress. Front Neurosci. 2014;8: 456.

14.Filipovic, D., Todorovic, N., Bernardi, R. E. Gass, P. Oxidative and nitrosative stress pathways in the brain of socially isolated adult male rats demonstrating depressive- and anxiety-like symptoms. Brain Struct Funct. 2017;222ख1凶: 1-20.

15.Jiang, Y., Botchway, B. O. A., Hu, Z. Fang, M. Overexpression of SIRT1 Inhibits Corticosterone-Induced Autophagy. Neuroscience. 2019;411: 11-22.

16.de Lima-Seolin, B. G., Nemec-Bakk, A., Forsyth, H., Kirk, S., da Rosa Araujo, A. S., Schenkel, P. C. et al. Bucindolol Modulates Cardiac Remodeling by Attenuating Oxidative Stress in H9c2 Cardiac Cells Exposed to Norepinephrine. Oxid Med Cell Longev. 2019;2019: 6325424.

17.Manyonda, I. T., Slater, D. M., Fenske, C., Hole, D., Choy, M. Y. Wilson, C. A role for noradrenaline in preeclampsia: towards a unifying hypothesis for the pathophysiology. Br J Obstet Gynaecol. 1998;105囚6ম: 641-8.

18.Madden, K. S. Catecholamines, sympathetic innervation, and immunity. Brain Behav Immun. 2003;17 Suppl 1: S5-10.

19.Chen, Q., Zhang, Y., Peng, H., Lei, L., Kuang, H., Zhang, L. et al. Transient \{beta\}2-adrenoceptor activation confers pregnancy loss by disrupting embryo spacing at implantation. J Biol Chem. 2011;286 \6冈: 4349-56.

20.Correia-da-Silva, G., Bell, S. C., Pringle, J. H. Teixeira, N. A. Patterns of uterine cellular proliferation and apoptosis in the implantation site of the rat during pregnancy. Placenta. 2004;25『6:: 538-47.

21.Liu, G., Dong, Y., Wang, Z., Cao, J. Chen, Y. Restraint stress delays endometrial adaptive remodeling during mouse embryo implantation. Stress. 2015;18®6冈: 699-709.

22.Walsh, D. A., Perkins, J. P. Krebs, E. G. An adenosine 3',5'-monophosphate-dependant protein kinase from rabbit skeletal muscle. J Biol Chem. 1968;243凶13®: 3763-5.

23.Bruzzone, A., Sauliere, A., Finana, F., Senard, J. M., Luthy, I. Gales, C. Dosage-dependent regulation of cell proliferation and adhesion through dual beta2-adrenergic receptor/cAMP signals. FASEB J. 2014;28 \3: 1342-54. 
24.Hasegawa, K., Iwai-Kanai, E. Sasayama, S. Neurohormonal regulation of myocardial cell apoptosis during the development of heart failure. J Cell Physiol. 2001;186囚1囚: 11-8.

25.Fajardo, G., Zhao, M., Berry, G., Wong, L. J., Mochly-Rosen, D. Bernstein, D. beta2-adrenergic receptors mediate cardioprotection through crosstalk with mitochondrial cell death pathways. J Mol Cell Cardiol. 2011;51ه5:: 781-9.

26.Burniston, J. G., Tan, L. B. Goldspink, D. F. beta2-Adrenergic receptor stimulation in vivo induces apoptosis in the rat heart and soleus muscle. J Appl Physiol. 2005;98®4囚: 1379-86.

27.Micova, P., Hahnova, K., Hlavackova, M., Elsnicova, B., Chytilova, A., Holzerova, K. et al. Chronic intermittent hypoxia affects the cytosolic phospholipase A2alpha/cyclooxygenase 2 pathway via beta2adrenoceptor-mediated ERK/p38 stimulation. Mol Cell Biochem. 2016;423囚1-2邓: 151-63.

28.Zhao, M., Wimmer, A., Trieu, K., Discipio, R. G. Schraufstatter, I. U. Arrestin regulates MAPK activation and prevents NADPH oxidase-dependent death of cells expressing CXCR2. J Biol Chem. 2004;279『47凶: 49259-67.

29.Yano, M., Ikeda, M., Abe, K., Kawai, Y., Kuroki, M., Mori, K. et al. Oxidative stress induces anti-hepatitis C virus status via the activation of extracellular signal-regulated kinase. Hepatology. 2009;50囚3囚: 678-88.

30.Qian, Y., Cao, L., Guan, T., Chen, L., Xin, H., Li, Y. et al. Protection by genistein on cortical neurons against oxidative stress injury via inhibition of NF-kappaB, JNK and ERK signaling pathway. Pharm Biol. 2015;53囚8囚: 1124-32.

31.Zhang, S., Qi, Y., Xu, Y., Han, X., Peng, J., Liu, K. et al. Protective effect of flavonoid-rich extract from Rosa laevigata Michx on cerebral ischemia-reperfusion injury through suppression of apoptosis and inflammation. Neurochem Int. 2013;63囚5囚: 522-32.

32.Dwir, D., Giangreco, B., Xin, L., Tenenbaum, L., Cabungcal, J. H., Steullet, P. et al. MMP9/RAGE pathway overactivation mediates redox dysregulation and neuroinflammation, leading to inhibitory/excitatory imbalance: a reverse translation study in schizophrenia patients. Mol Psychiatry. 2019.

33.Fan, M., Xu, Y., Hong, F., Gao, X., Xin, G., Hong, H. et al. Rac1/beta-Catenin Signalling Pathway Contributes to Trophoblast Cell Invasion by Targeting Snail and MMP9. Cell Physiol Biochem. 2016;38 \4: 1319-32.

34.Olejarz, W., Bryk, D., Zapolska-Downar, D., Malecki, M., Stachurska, A. Sitkiewicz, D. Mycophenolic acid attenuates the tumour necrosis factor-alpha-mediated proinflammatory response in endothelial cells by blocking the MAPK/NF-kappaB and ROS pathways. Eur J Clin Invest. 2014;44囚1囚: 54-64.

35.Burroughs Pena, M. S., Mbassa, R. S., Slopen, N. B., Williams, D. R., Buring, J. E. Albert, M. A. Cumulative Psychosocial Stress and Ideal Cardiovascular Health in Older Women. Circulation. 2019;139 囚17囚: 2012-21. 
36.Bot, I. Kuiper, J. Stressed brain, stressed heart? Lancet. 2017;389ه10071囚: 770-1.

37.Kivimaki, M., Pentti, J., Ferrie, J. E., Batty, G. D., Nyberg, S. T., Jokela, M. et al. Work stress and risk of death in men and women with and without cardiometabolic disease: a multicohort study. Lancet Diabetes Endocrinol. 2018;6®9®: 705-13.

38.Nagatomo, Y., McNamara, D. M., Alexis, J. D., Cooper, L. T., Dec, G. W., Pauly, D. F. et al. Myocardial Recovery in Patients With Systolic Heart Failure and Autoantibodies Against beta1-Adrenergic Receptors. J Am Coll Cardiol. 2017;69『8囚: 968-77.

39.Grisanti, L. A., Gumpert, A. M., Traynham, C. J., Gorsky, J. E., Repas, A. A., Gao, E. et al. LeukocyteExpressed beta2-Adrenergic Receptors Are Essential for Survival After Acute Myocardial Injury. Circulation. 2016;134『2®: 153-67.

40.Salk, R. H., Hyde, J. S. Abramson, L. Y. Gender differences in depression in representative national samples: Meta-analyses of diagnoses and symptoms. Psychol Bull. 2017;143凶8囚: 783-822.

41.Chuang, J. C., Krishnan, V., Yu, H. G., Mason, B., Cui, H., Wilkinson, M. B. et al. A beta3-adrenergic-leptinmelanocortin circuit regulates behavioral and metabolic changes induced by chronic stress. Biol Psychiatry. 2010;67囚11囚: 1075-82.

42.de Quervain, D. J., Aerni, A. Roozendaal, B. Preventive effect of beta-adrenoceptor blockade on glucocorticoid-induced memory retrieval deficits. Am J Psychiatry. 2007;164『6『: 967-9.

43.Gavin, N. I., Gaynes, B. N., Lohr, K. N., Meltzer-Brody, S., Gartlehner, G. Swinson, T. Perinatal depression: a systematic review of prevalence and incidence. Obstet Gynecol. 2005;106ه5 Pt 1囚: 1071-83.

44.Monk, C., Newport, D. J., Korotkin, J. H., Long, Q., Knight, B. Stowe, Z. N. Uterine blood flow in a psychiatric population: impact of maternal depression, anxiety, and psychotropic medication. Biol Psychiatry. 2012;72ख6囚: 483-90.

45.Dreiling, M., Schiffner, R., Bischoff, S., Rupprecht, S., Kroegel, N., Schubert, H. et al. Impact of chronic maternal stress during early gestation on maternal-fetal stress transfer and fetal stress sensitivity in sheep. Stress. 2018;21区1区: 1-10.

46.Ramot, A., Jiang, Z., Tian, J. B., Nahum, T., Kuperman, Y., Justice, N. et al. Hypothalamic CRFR1 is essential for HPA axis regulation following chronic stress. Nat Neurosci. 2017;20®3囚: 385-8.

47.Wood, S. K. Valentino, R. J. The brain norepinephrine system, stress and cardiovascular vulnerability. Neurosci Biobehav Rev. 2017;74囚Pt B囚: 393-400.

48.Rajbhandari, A. K., Baldo, B. A. Bakshi, V. P. Predator Stress-Induced CRF Release Causes Enduring Sensitization of Basolateral Amygdala Norepinephrine Systems that Promote PTSD-Like Startle Abnormalities. J Neurosci. 2015;35囚42邓: 14270-85. 
49.Kolmus, K., Tavernier, J. Gerlo, S. beta2-Adrenergic receptors in immunity and inflammation: stressing NF-kappaB. Brain Behav Immun. 2015;45:297-310.

50.Rosengren, A., Hawken, S., Ounpuu, S., Sliwa, K., Zubaid, M., Almahmeed, W. A. et al. Association of psychosocial risk factors with risk of acute myocardial infarction in 11119 cases and 13648 controls from 52 countries (the INTERHEART study): case-control study. Lancet. 2004;364『9438囚: 953-62.

51.Barrett, E. S., Vitek, W., Mbowe, O., Thurston, S. W., Legro, R. S., Alvero, R. et al. Allostatic load, a measure of chronic physiological stress, is associated with pregnancy outcomes, but not fertility, among women with unexplained infertility. Hum Reprod. 2018;33凶9凶: 1757-66.

52.Lampinen, K. H., Ronnback, M., Groop, P. H., Nicholls, M. G., Yandle, T. G. Kaaja, R. J. Increased plasma norepinephrine levels in previously pre-eclamptic women. J Hum Hypertens. 2014;28®4囚: 269-73.

53.Newport, D. J., Hostetter, A. L., Juul, S. H., Porterfield, S. M., Knight, B. T. Stowe, Z. N. Prenatal Psychostimulant and Antidepressant Exposure and Risk of Hypertensive Disorders of Pregnancy. J Clin Psychiatry. 2016;77ه11囚: 1538-45.

54.Sugama, S., Sekiyama, K., Kodama, T., Takamatsu, Y., Takenouchi, T., Hashimoto, M. et al. Chronic restraint stress triggers dopaminergic and noradrenergic neurodegeneration: Possible role of chronic stress in the onset of Parkinson's disease. Brain Behav Immun. 2016;51:39-46.

55.Hoffman, R. P., Sinkey, C. A., Dopp, J. M. Phillips, B. G. Lack of effect of alpha- and beta-adrenergic inhibition on forearm glucose uptake despite differences in forearm blood flow in healthy humans. Metabolism. 2002;51⿴11区: 1506-13.

56.Fagerholm, V., Rokka, J., Nyman, L., Sallinen, J., Tiihonen, J., Tupala, E. et al. Autoradiographic characterization of alpha(2C)-adrenoceptors in the human striatum. Synapse. 2008;62邓7邓: 508-15.

57.Jeong, J. Y., Lee, D. H. Kang, S. S. Effects of chronic restraint stress on body weight, food intake, and hypothalamic gene expressions in mice. Endocrinol Metab (Seoul). 2013;28『4囚: 288-96.

58.Komorita, Y., Iwase, M., Fujii, H., Ohkuma, T., Ide, H., Jodai-Kitamura, T. et al. Impact of Body Weight Loss From Maximum Weight on Fragility Bone Fractures in Japanese Patients With Type 2 Diabetes: The Fukuoka Diabetes Registry. Diabetes care. 2018;41凶5凶: 1061-7.

59.Lassen, J. F., Botker, H. E. Terkelsen, C. J. Timely and optimal treatment of patients with STEMI. Nat Rev Cardiol. 2013;10ه1囚: 41-8.

60.Droge, W. Free radicals in the physiological control of cell function. Physiol Rev. 2002;82ه1囚: 47-95.

61.Tiwari, M., Prasad, S., Tripathi, A., Pandey, A. N., Ali, I., Singh, A. K. et al. Apoptosis in mammalian oocytes: a review. Apoptosis. 2015;20冈8囚: 1019-25. 
62.Joshi, A., Mahfooz, S., Maurya, V. K., Kumar, V., Basanna, C. S., Kaur, G. et al. PARP1 during embryo implantation and its upregulation by oestradiol in mice. Reproduction. 2014;147囚6囚: 765-80.

63.Bengatta, S., Arnould, C., Letavernier, E., Monge, M., de Preneuf, H. M., Werb, Z. et al. MMP9 and SCF protect from apoptosis in acute kidney injury. Journal of the American Society of Nephrology : JASN. 2009;20囚4囚: 787-97.

64.Dai, C., Zhang, B., Liu, X., Guo, K., Ma, S., Cai, F. et al. Pyrimethamine sensitizes pituitary adenomas cells to temozolomide through cathepsin B-dependent and caspase-dependent apoptotic pathways. Int J Cancer . 2013;133®8®: 1982-93.

65.Plaks, V., Rinkenberger, J., Dai, J., Flannery, M., Sund, M., Kanasaki, K. et al. Matrix metalloproteinase-9 deficiency phenocopies features of preeclampsia and intrauterine growth restriction. Proc Natl Acad Sci U S A. 2013;110冈27凶: 11109-14.

66.Wallace, K., Cornelius, D. C., Scott, J., Heath, J., Moseley, J., Chatman, K. et al. CD4+ T cells are important mediators of oxidative stress that cause hypertension in response to placental ischemia. Hypertension. 2014;64『5区: 1151-8.

67.Ferguson, K. K., Cantonwine, D. E., McElrath, T. F., Mukherjee, B. Meeker, J. D. Repeated measures analysis of associations between urinary bisphenol-A concentrations and biomarkers of inflammation and oxidative stress in pregnancy. Reprod Toxicol. 2016;6693-98.

68.Kumar, V., Palermo, R., Talora, C., Campese, A. F., Checquolo, S., Bellavia, D. et al. Notch and NF-kB signaling pathways regulate miR-223/FBXW7 axis in T-cell acute lymphoblastic leukemia. Leukemia. 2014;28囚12邓: 2324-35.

69.De Simone, V., Franze, E., Ronchetti, G., Colantoni, A., Fantini, M. C., Di Fusco, D. et al. Th17-type cytokines, IL-6 and TNF-alpha synergistically activate STAT3 and NF-kB to promote colorectal cancer cell growth. Oncogene. 2015;34囚27邓: 3493-503.

70.Aeschlimann, F. A., Batu, E. D., Canna, S. W., Go, E., Gul, A., Hoffmann, P. et al. A20 haploinsufficiency (HA20): clinical phenotypes and disease course of patients with a newly recognised NF-kB-mediated autoinflammatory disease. Ann Rheum Dis. 2018;77『5®: 728-35.

71.Kim, J., Lee, K. S., Kim, J. H., Lee, D. K., Park, M., Choi, S. et al. Aspirin prevents TNF-alpha-induced endothelial cell dysfunction by regulating the NF-kappaB-dependent miR-155/eNOS pathway: Role of a miR-155/eNOS axis in preeclampsia. Free Radic Biol Med. 2017;104:185-98.

72.Somensi, N., Brum, P. O., de Miranda Ramos, V., Gasparotto, J., Zanotto-Filho, A., Rostirolla, D. C. et al. Extracellular HSP70 Activates ERK1/2, NF-kB and Pro-Inflammatory Gene Transcription Through Binding with RAGE in A549 Human Lung Cancer Cells. Cell Physiol Biochem. 2017;42ه6囚: 2507-22. 
73.Qiu, L. L., Wang, C., Yao, S., Li, N., Hu, Y., Yu, Y. et al. Fenvalerate induces oxidative hepatic lesions through an overload of intracellular calcium triggered by the ERK/IKK/NF-kappaB pathway. FASEB J. 2019;33囚2ख: 2782-95.

74.Guan, L., Jia, N., Zhao, X., Zhang, X., Tang, G., Yang, L. et al. The involvement of ERK/CREB/Bcl-2 in depression-like behavior in prenatally stressed offspring rats. Brain Res Bull. 2013;99:1-8.

75.Philipp, M. Hein, L. Adrenergic receptor knockout mice: distinct functions of 9 receptor subtypes. Pharmacol Ther. 2004;101ه1囚: 65-74.

76.Mak, S. Newton, G. E. Vitamin C augments the inotropic response to dobutamine in humans with normal left ventricular function. Circulation. 2001;103®6邓: 826-30.

77.Zhang, G. X., Kimura, S., Nishiyama, A., Shokoji, T., Rahman, M., Yao, L. et al. Cardiac oxidative stress in acute and chronic isoproterenol-infused rats. Cardiovasc Res. 2005;65囚1ख: 230-8.

78.Bruzzone, M. E., Fabres, C., Benitez, D. A., Castellon, E. A. Zegers-Hochschild, F. Influence of embryonic conditioned media upon the endometrial beta-adrenergic receptor. Reprod Biomed Online. 2005;11凶1区: 5863.

79.Bazzano, M. V., Sarrible, G. B., Martinez, N., Beron de Astrada, M. Elia, E. M. Obesity alters the uterine environment before pregnancy. J Nutr Biochem. 2018;62:181-91.

80.Singh, K., Xiao, L., Remondino, A., Sawyer, D. B. Colucci, W. S. Adrenergic regulation of cardiac myocyte apoptosis. J Cell Physiol. 2001;189®3囚: 257-65.

81.Chandrasekar, B., Marelli-Berg, F. M., Tone, M., Bysani, S., Prabhu, S. D. Murray, D. R. Beta-adrenergic stimulation induces interleukin-18 expression via beta2-AR, PI3K, Akt, IKK, and NF-kappaB. Biochem Biophys Res Commun. 2004;319®2邓: 304-11.

82.Sun, F., Yang, X. J., Lv, H. Y., Tang, Y. B., An, S. M., Ding, X. P. et al. beta2-Adrenoreceptor-Mediated Proliferation Inhibition of Embryonic Pluripotent Stem Cells. J Cell Physiol. 2015;230冈11邓: 2640-6.

83.Zhuang, C., Liu, D., Yang, X., Wang, H., Han, L. Li, Y. The immunotoxicity of aluminum trichloride on rat peritoneal macrophages via beta2-adrenoceptors/cAMP pathway acted by norepinephrine. Chemosphere. 2016;149:34-40.

84.Kim, S., Bakre, M., Yin, H. Varner, J. A. Inhibition of endothelial cell survival and angiogenesis by protein kinase A. J Clin Invest. 2002;110冈7囚: 933-41.

85.Li, H., Yang, S., Wu, J., Ji, L., Zhu, L., Cao, L. et al. cAMP/PKA signaling pathway contributes to neuronal apoptosis via regulating IDE expression in a mixed model of type 2 diabetes and Alzheimer's disease. J Cell Biochem. 2018;119ه2邓: 1616-26. 
86.Zhang, J., Feng, J., Ma, D., Wang, F., Wang, Y., Li, C. et al. Neuroprotective Mitochondrial Remodeling by AKAP121/PKA Protects HT22 Cell from Glutamate-Induced Oxidative Stress. Mol Neurobiol.

2019;56(8):5586-607.

87.Lv, C., Fu, S., Dong, Q., Yu, Z., Zhang, G., Kong, C. et al. PAGE4 promotes prostate cancer cells survive under oxidative stress through modulating MAPK/JNK/ERK pathway. J Exp Clin Cancer Res. 2019;38ه1囚: 24.

88.D'Oria, R., Laviola, L., Giorgino, F., Unfer, V., Bettocchi, S. Scioscia, M. PKB/Akt and MAPK/ERK phosphorylation is highly induced by inositols: Novel potential insights in endothelial dysfunction in preeclampsia. Pregnancy Hypertens. 2017;10:107-12.

89.Qian, L., Hu, X., Zhang, D., Snyder, A., Wu, H. M., Li, Y. et al. beta2 Adrenergic receptor activation induces microglial NADPH oxidase activation and dopaminergic neurotoxicity through an ERK-dependent/protein kinase A-independent pathway. Glia. 2009;57囚15区: 1600-9.

90.Zhou, Q. L., Wang, T. Y., Li, M. Shang, Y. X. Alleviating airway inflammation by inhibiting ERK-NFkappaB signaling pathway by blocking Kv1.3 channels. Int Immunopharmacol. 2018;63:110-8.

\section{Declarations}

\section{Ethics approval and consent to participate}

In my manuscript, all animal procedures were approved by the China Agricultural University Institutional Animal Care and Use Committee (AW18079102-3-2).

\section{Consent for publication}

My manuscript does not contain data from any individual person, this section is not applicable in my manuscript.

\section{Availability of data and materials}

All data supporting the conclusion of this article are included in this published article.

\section{Competing interests}

The authors declare that they have no competing interests.

\section{Funding}

The present study work was supported by the National Natural Science Foundation of China (grant nos. 31972633, 31572476, 31272483) and National Natural Science Foundation of Beijing (grant nos. 6172022). 


\section{Authors' contributions}

JYL, GHL and YLD designed the experiments. GHL carried out the experiments and interpreted the data. ZXW and JC checked the figures. JYL and YLD wrote the manuscript. YXC checked the manuscript.

\section{Acknowledgements}

The authors are grateful for the experimental animal platform of China Agricultural University for their support for this research. The authors acknowledge the comments of the reviewers that helped to improve the study.

\section{Authors' information}

Laboratory of Neurobiology, College of Veterinary Medicine, China Agricultural University, No. 2, Yuanmingyuan West Road, Haidian District, Beijing 100193, Beijing, People's Republic of China.

Jiayin Lu, lujiayin2013@163.com

Guanhui Liu,375036744@qq.com

Zixu Wang, zxwang2007@163.com

Jing Cao, caojing315@126.com

Yaoxing Chen, yxchen@cau.edu.cn

Yulan Dong, ylbcdong@cau.edu.cn

The First Author: Jiayin Lu lujiayin2013@163.com

Co-Corresponding Author: Yulan Dong ylbcdong@cau.edu.cn

Yaoxing Chen yxchen@cau.edu.cn

\section{Figures}




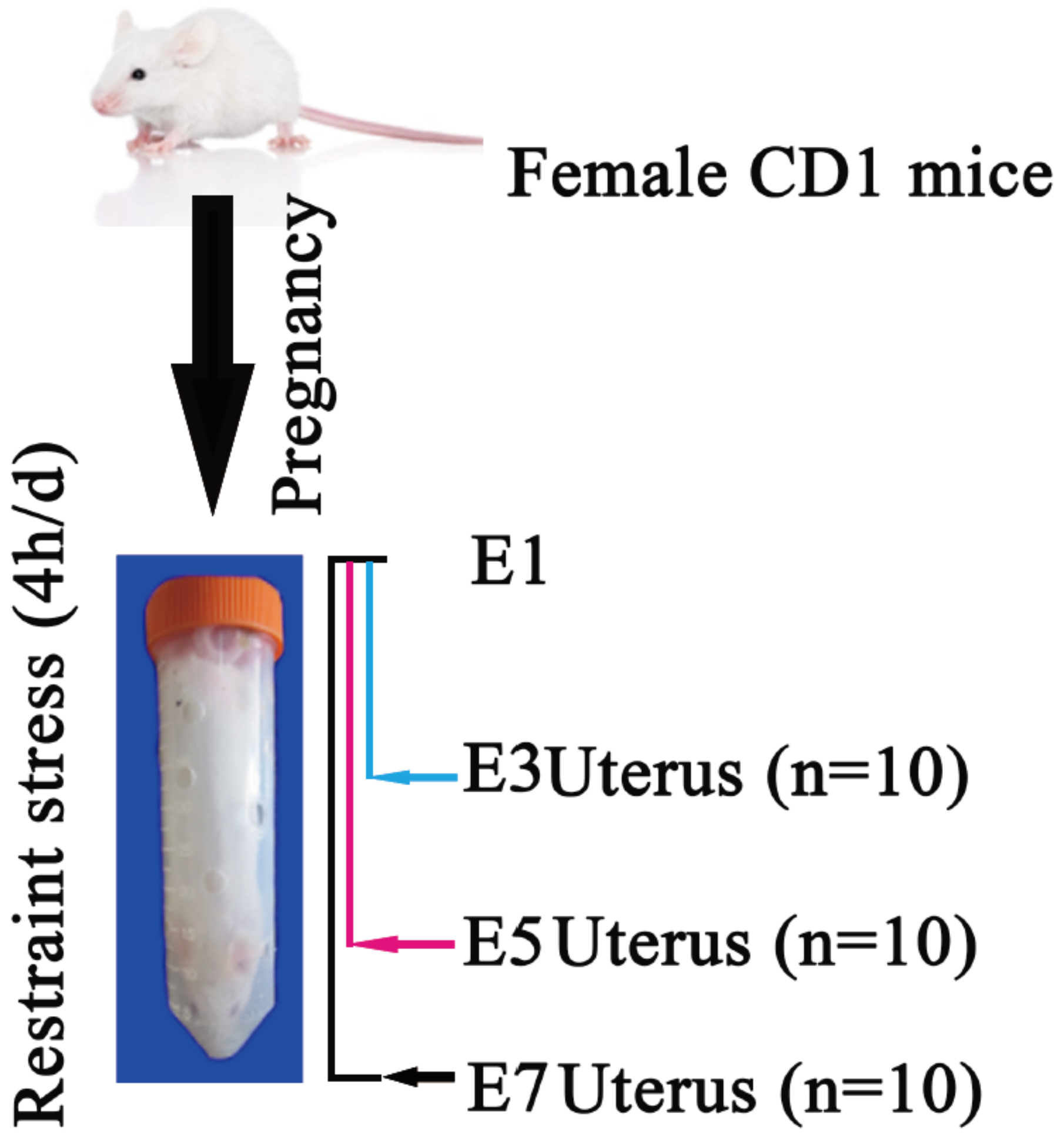

Figure 1

Schematic representation of the animal model used in this study. E1: Embryonic day 1; E3: Embryonic day 3; E5: Embryonic day 5; E7: Embryonic day 7. There were 200 pregnant mice. Sixty mice were used to perform a molecular biology test (E3: restraint stress group= 10 mice, control group=10 mice; E5: restraint stress group $=10$ mice, control group $=10$ mice; E7: restraint stress group $=10$ mice, control group $=10$ mice). Seven mice were used to measure the expression of protein and mRNA. Therefore, the uterus of 
each mouse was divided into two parts. Three mice were used for immunochemistry. The remaining mice were used for cell culture.
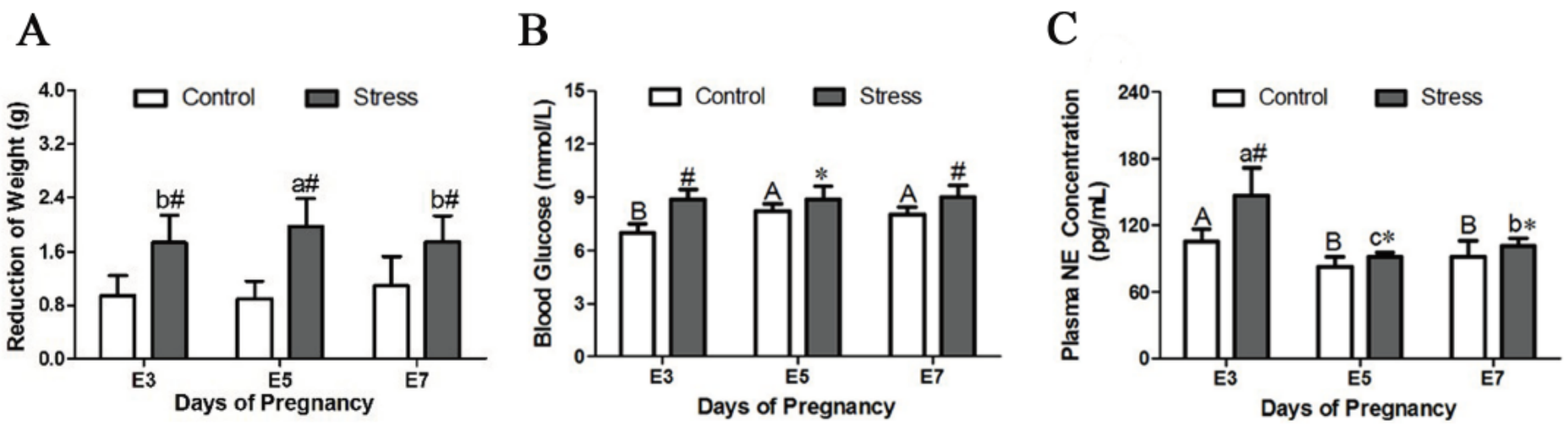

Figure 2

Effects of restraint stress on reductions in weight and the concentrations of NE and blood glucose in the plasma of pregnant mice. After restraint stress treatment, body weight reduction was significantly enhanced. Restraint stress treatment caused an increase in plasma NE levels and blood glucose levels. The uppercase letters represent differences in the control group among E3, E5, and E7, and the lowercase letters represent differences in the stressed group among E3, E5, and E7 (P $\leq 0.05)$. ${ }^{*} \leq 0.05$ and \#P $\leq$ 0.01 are used to denote significance compared with the corresponding control groups.
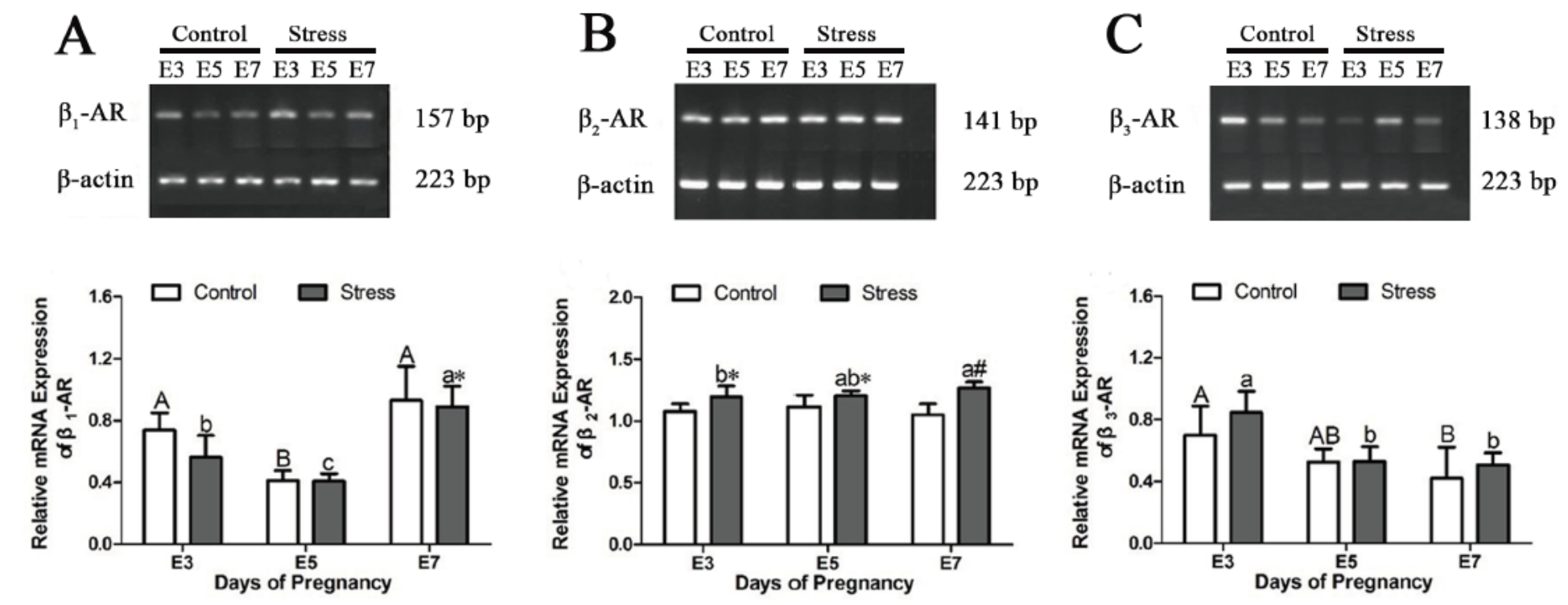

\section{Figure 3}

The relative expression of uterine $\beta 1-A R, \beta 2-A R$ and $\beta 3-A R$ mRNA in pregnant mice. Only $\beta 2-A R$ showed a significant increase after restraint stress during early pregnancy. The uppercase letters represent differences in the control group among E3, E5 and E7, 5, and 7, and the lowercase letters represent 
differences in the stressed group among E3, E5 and E7 (P $\leq 0.05)$. ${ }^{*} \leq 0.05$ and $\# P \leq 0.01$ are used to denote significance compared with the corresponding control groups.
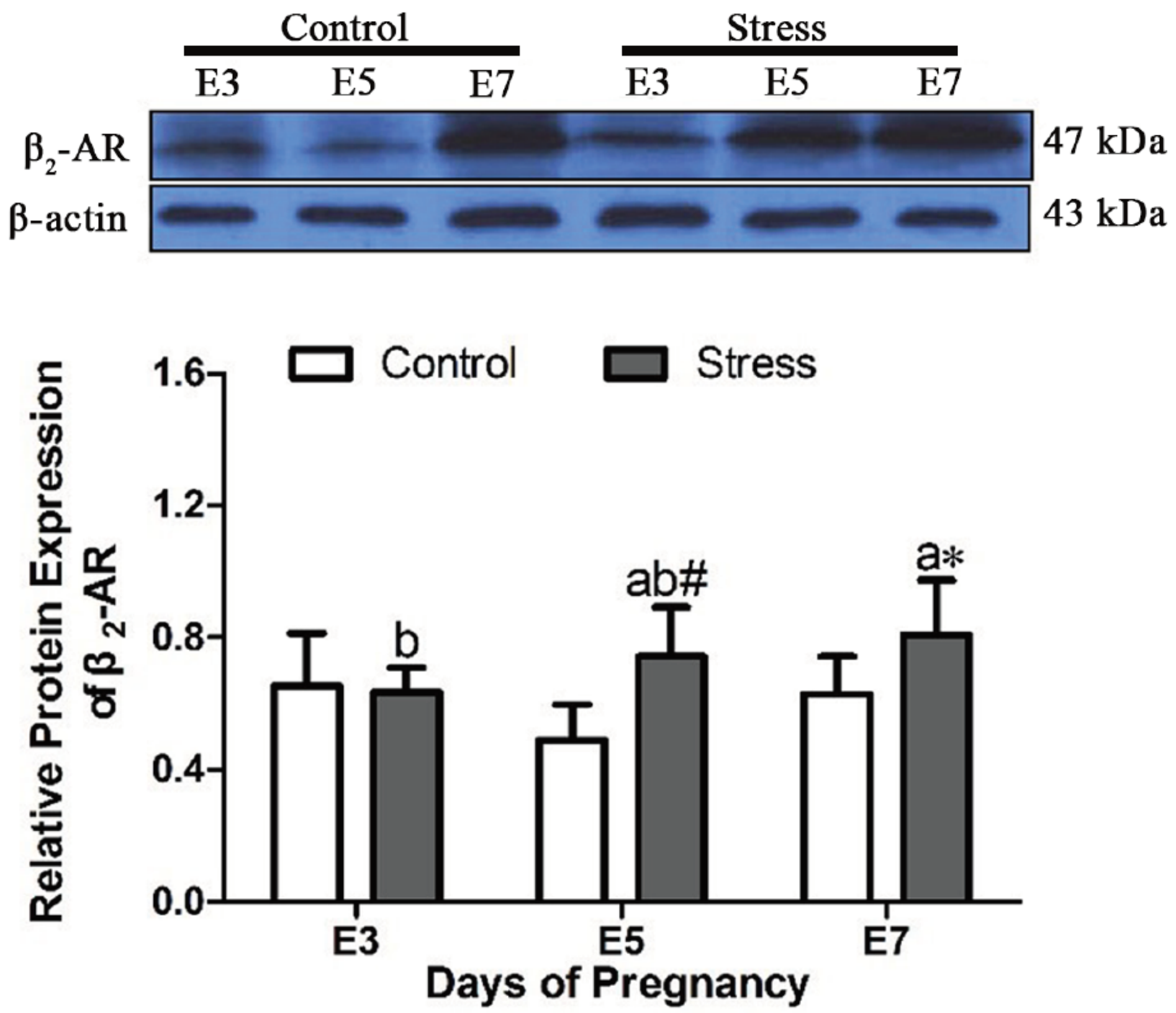

Figure 4

Effects of restraint stress on the relative protein expression of $\beta 2-A R$ in the uteri of pregnant mice. After restraint stress treatment, the expression of $\beta 2$-AR protein in uterine tissue was increased, and the content of $\beta 2$-AR protein was not affected by gestational age. The uppercase letters represent differences in the control group among E3, E5 and E7, and the lowercase letters represent differences in the stressed group among E3, E5 and E7 ( $\mathrm{P} \leq 0.05)$. ${ }^{*} \mathrm{P} \leq 0.05$ and $\# \mathrm{P} \leq 0.01$ are used to denote significance compared with the corresponding control groups. 
Figure 5

Immunohistochemical localization of $\beta 2-A R$ in the uteri of pregnant mice. Localized expression of $\beta 2-A R$ in the uterus on different gestational ages. $A$ and $B$ show $\beta 2$-AR-positive cells in the myometrium. $C, D$ and $E$ show $\beta 2$-AR-positive cells in the endometria of the uteri of pregnant mice on E3, E5 and E7, respectively. F shows $\beta 2$-AR-negative cells. Bar $=50 \mu \mathrm{m}$.

A
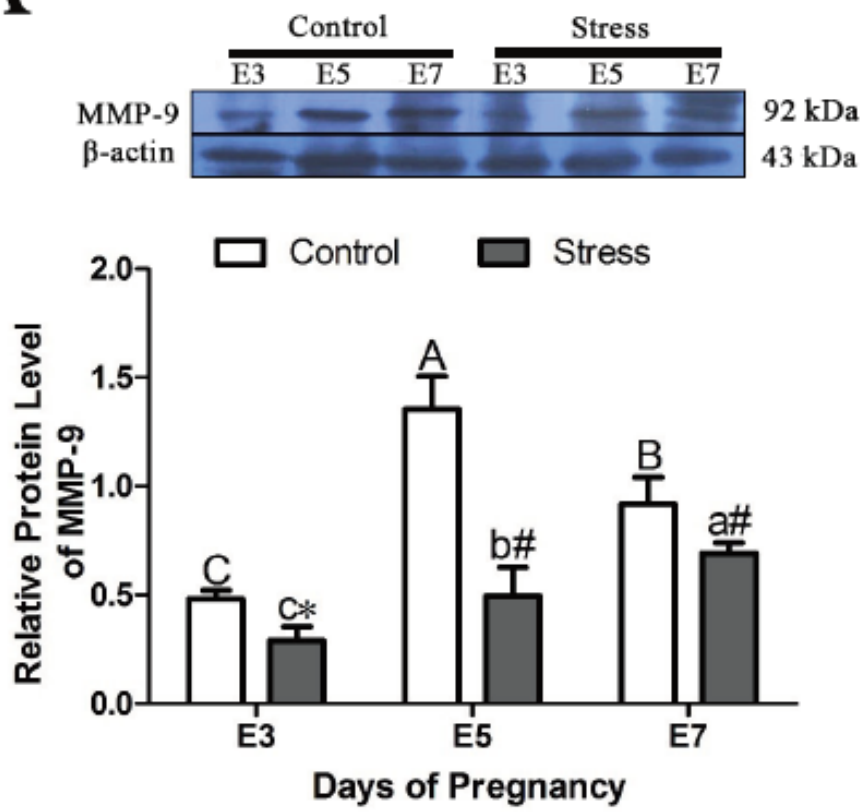

C
B
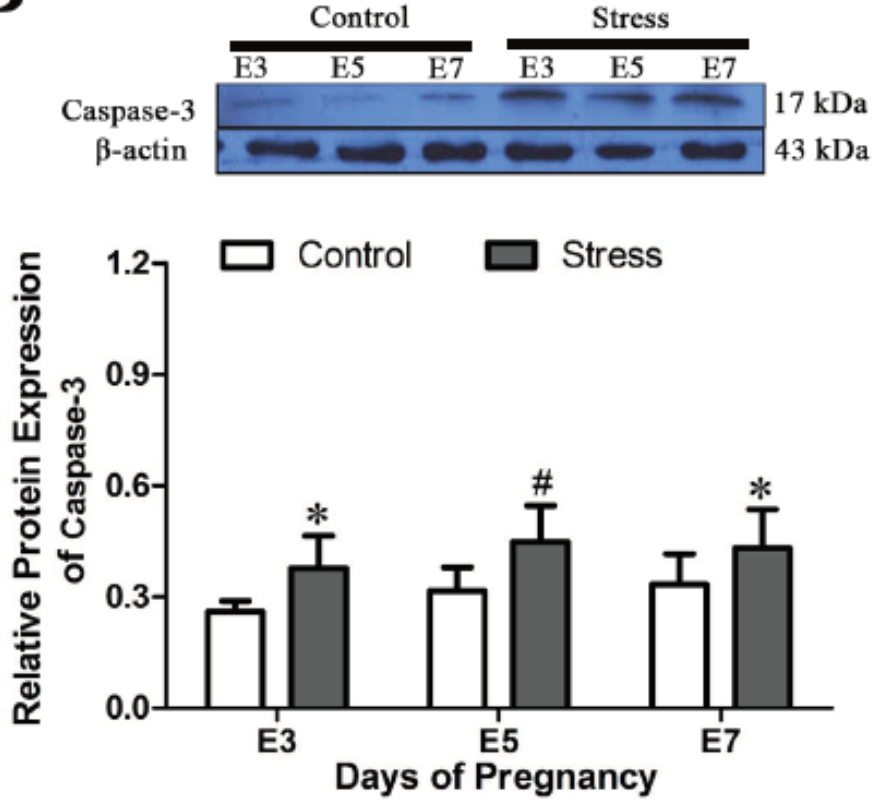

D
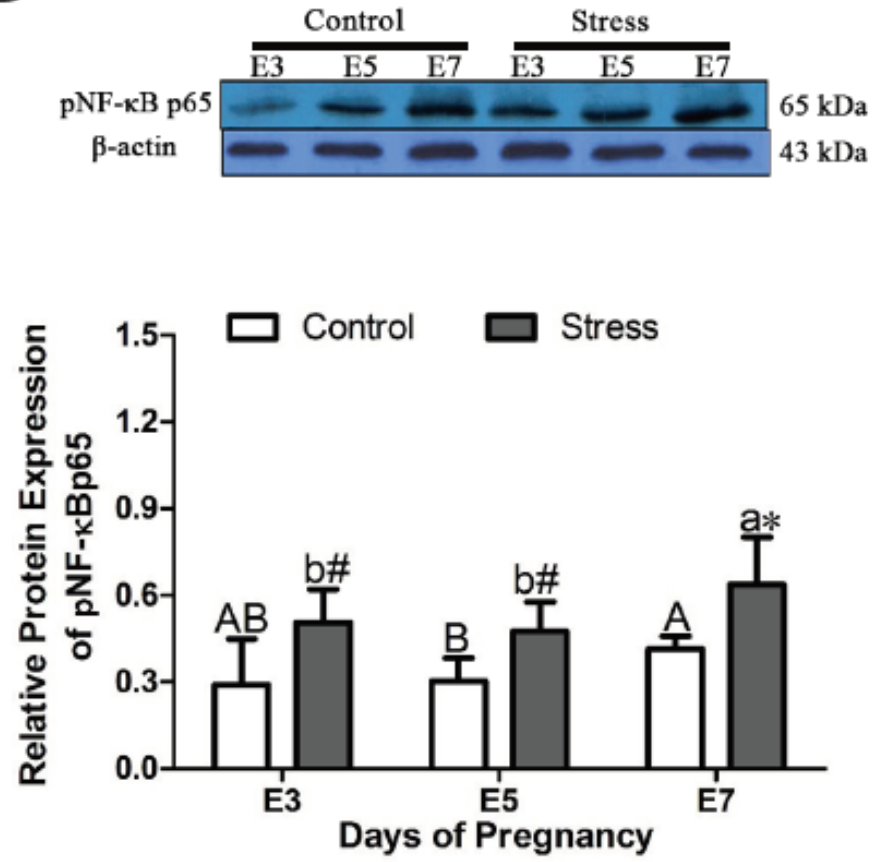

Figure 6

Effects of restraint stress on the relative protein levels of MMP-9, Caspase-3, ERK1/2 and pNF-KB p65 in the uteri of pregnant mice. MMP-9 protein expression in the uterus was affected by gestational age and 
restraint stress treatment. (B) Caspase- 3 protein content in uterine tissue was not affected by gestational age and was only affected by restraint stress treatment. (C) The level of pERK $1 / 2$ protein in uterine tissue was not affected by gestational age and was only affected by restraint stress treatment. (D) The pNF-KB p65 protein content in uterine tissue was affected by gestational age and restraint stress treatment. The uppercase letters represent differences in the control group amongE3, E5 and E7, and the lowercase letters represent differences in the stressed group among E3, E5 and E7 $(P \leq 0.05)$. ${ }^{*} \leq 0.05$ and $\# P \leq$ 0.01 are used to denote significance compared with the corresponding control groups.

A

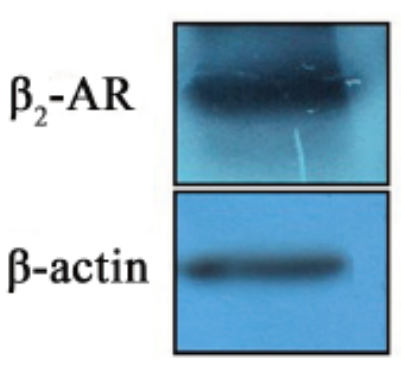

$\mathrm{C}$

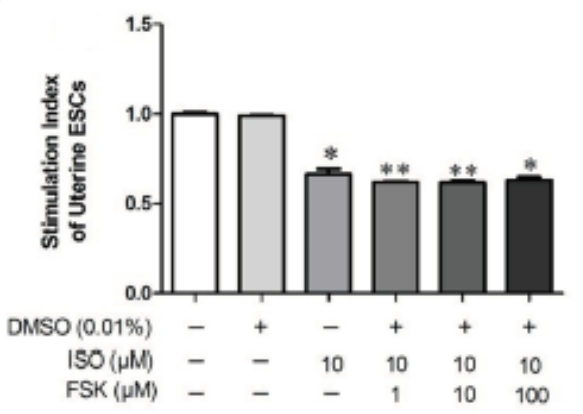

$\mathrm{E}$

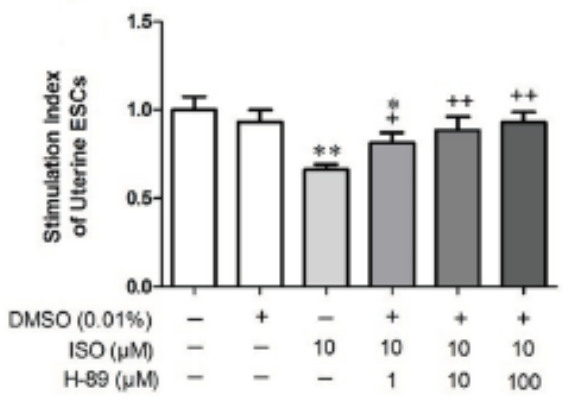

G

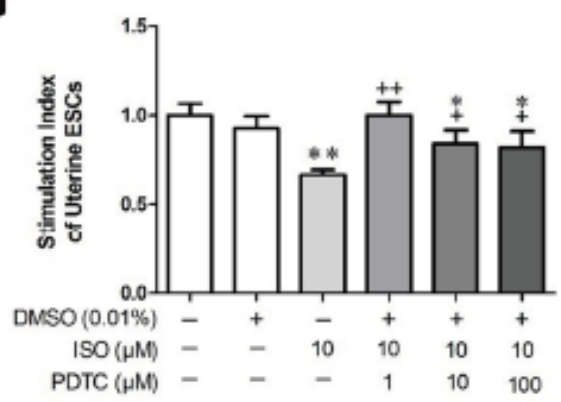

B

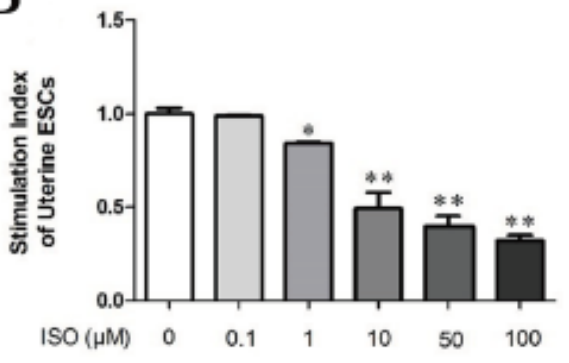

D

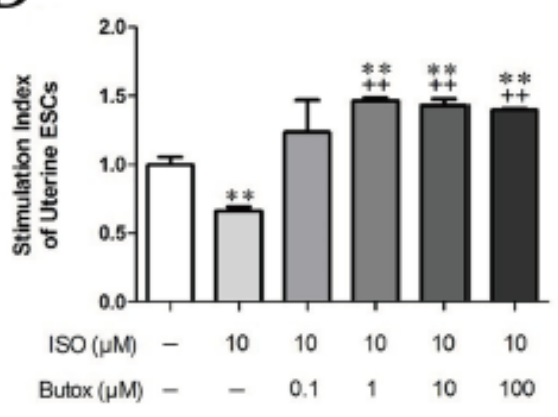

F

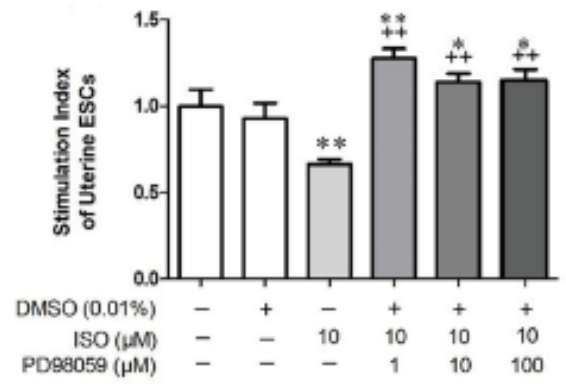

$\mathrm{H}$

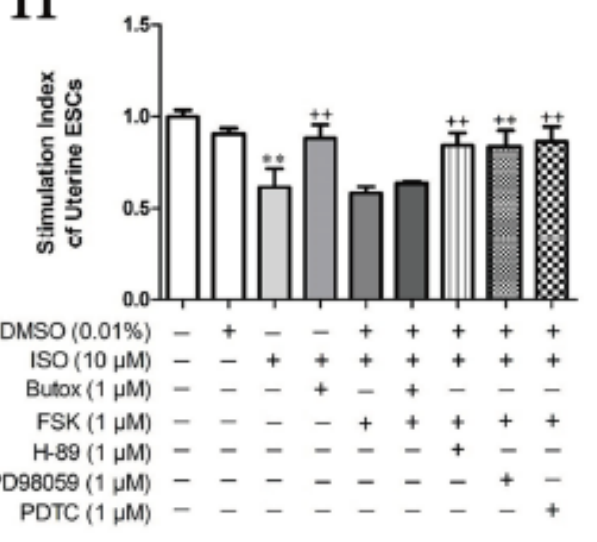




\section{Figure 7}

Effects of different drugs at different concentrations on the stimulation index of uterine ESCs from E5 pregnant mice. (A) $\beta 2-A R$ was expressed in primary endometrial stromal cells (ESCs). (B) ISO inhibited cell activity, and the suitable drug concentration was $10 \mu \mathrm{M}$. (C) FSK synergized with ISO to inhibit the proliferation of cells, and the suitable drug concentration was $1 \mu \mathrm{M}$. ${ }^{*} \mathrm{P} \leq 0.05$ and $* \star \mathrm{P} \leq 0.01$ are used to denote significance compared with the control group, $+P \leq 0.01$ and $++P \leq 0.01$ denote significance compared with the ISO-treated group. (D, E, F, G) Butox, H89, PD98059 and PDTC reversed the decrease in cell activity caused by ISO, and the suitable concentration for all drugs was $1 \mu \mathrm{M}$. ${ }^{*} \mathrm{P} \leq 0.05$ and ${ }^{* *} \mathrm{P} \leq$ 0.01 are used to denote significance compared with the control group, $+P \leq 0.01$ and $++P \leq 0.01$ denote significance compared with the ISO-treated group. $(\mathrm{H})$ The activation of $\beta 2$-AR inhibited the proliferation of ESCs mainly by activating the downstream ERK/MAPK signal through the CAMP/PKA pathway and inducing NF-KB signaling, thereby initiating apoptosis. ${ }^{* *} \mathrm{P} \leq 0.01$ is used to denote significance compared with the control group, and $++\mathrm{P} \leq 0.01$ denotes significance compared with the ISO-treated group.

A
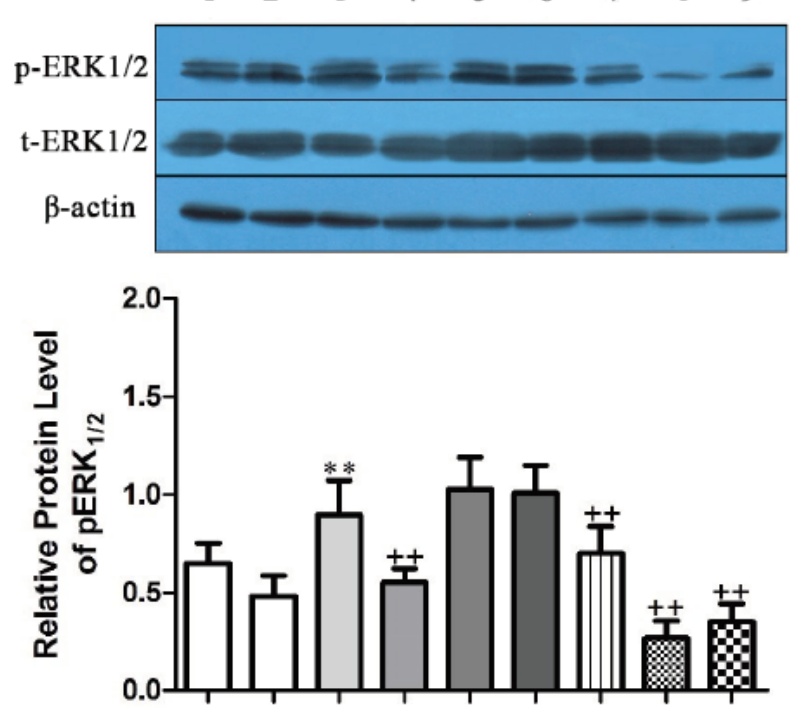

\begin{tabular}{|c|c|c|c|c|c|c|c|c|}
\hline DMSO (0.01\%) & - & + & - & - & + & + & + & + \\
\hline ISO (10 $\mu \mathrm{M})$ & - & - & + & + & + & + & + & + \\
\hline Butox (1 $\mu \mathrm{M})$ & - & - & - & + & - & + & - & - \\
\hline FSK (1 $\mu \mathrm{M})$ & - & - & - & - & + & + & + & + \\
\hline $\mathrm{H}-89(1 \mu \mathrm{M})$ & - & - & - & - & - & - & + & - \\
\hline 998059 (1 $\mu \mathrm{M})$ & 一 & 一 & - & - & - & - & - & + \\
\hline PDTC (1 $\mu \mathrm{M})$ & - & 一 & - & - & - & - & 一 & - \\
\hline
\end{tabular}

B

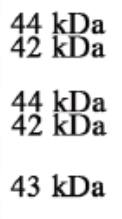

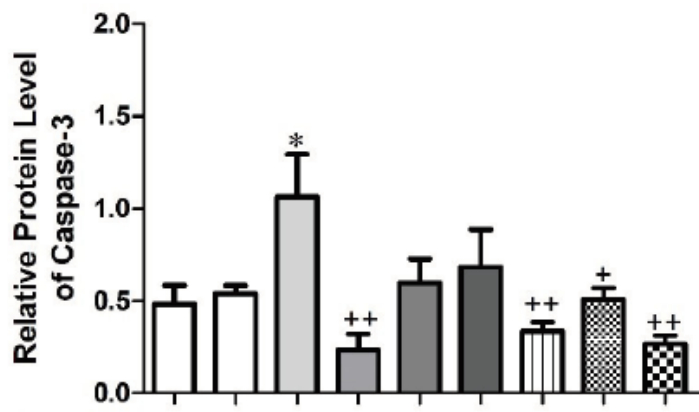

\begin{tabular}{|c|c|c|c|c|c|c|c|c|c|}
\hline DMSO (0.01\%) & - & + & - & - & + & + & + & + & + \\
\hline ISO (10 $\mu \mathrm{M})$ & - & - & + & + & + & + & + & + & + \\
\hline Butox $(1 \mu \mathrm{M})$ & - & - & - & + & - & + & - & - & - \\
\hline FSK $(1 \mu \mathrm{M})$ & - & - & - & - & + & + & + & + & + \\
\hline $\mathrm{H}-89(1 \mu \mathrm{M})$ & - & - & - & - & - & - & + & - & - \\
\hline $598059(1 \mu \mathrm{M})$ & - & - & - & - & - & - & - & + & - \\
\hline PDTC $(1 \mu \mathrm{M})$ & - & - & - & - & - & - & - & - & + \\
\hline
\end{tabular}

\section{Figure 8}

Effects of $\beta 2-A R / c A M P / P K A$ signaling on the relative protein levels of Caspase- 3 and ERK $1 / 2$ in uterine ESCs fromE5 pregnant mice. The activation of $\beta 2-A R$ promoted the apoptosis of ESCs mainly by activating downstream ERK/MAPK signaling through the CAMP/PKA pathway and inducing NF-KB activation, thereby initiating apoptosis. 1-9: (1) cells, (2) cells + 0.01\% DMSO, (3) cells + ISO, (4) cells + butoxamine + ISO, (5) cells + FSK+ ISO, (6) cells + butoxamine + ISO + FSK, (7) cells+ H-89 + ISO + FSK, 
(8) cells+PD98059+ ISO+ FSK, (9) cells + PDTC+ ISO+ FSK. *P $\leq 0.05$ is used to denote significance compared with the control group, $+\mathrm{P} \leq 0.05$ and $++\mathrm{P} \leq 0.01$ denote significance compared with the ISOtreated group.

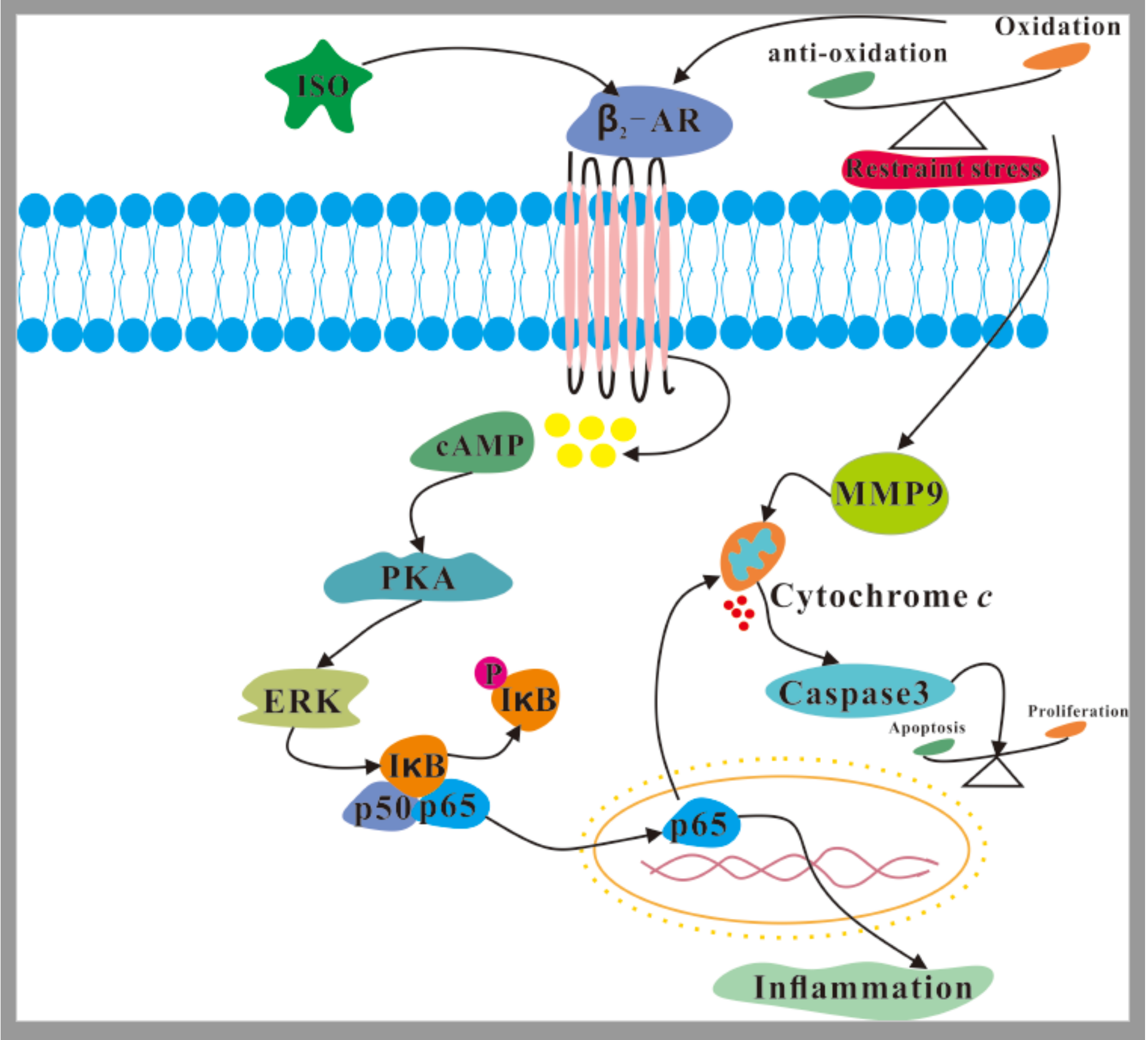

\section{Figure 9}

A schematic diagram of the $\beta 2-A R / c A M P / P K A$ pathway under restraint stress. Restraint stress disturbs the balance between antioxidation and oxidation and then promotes an increase in Caspase-3, which leads to an imbalance between apoptosis and proliferation. ERK is activated by the $\beta 2-A R / c A M P / P K A$ pathway, promoting apoptosis. Combined with our previous results, our findings suggest that ERK may induce inflammation by activating NF-kB p65. 